\title{
Review Article \\ Oral Complications in Hematopoietic Stem Cell Recipients: The Role of Inflammation
}

\author{
T. M. Haverman, ${ }^{1}$ J. E. Raber-Durlacher, ${ }^{2,3}$ W. M. H. Rademacher, ${ }^{1}$ \\ S. Vokurka, ${ }^{4}$ J. B. Epstein, ${ }^{5,6}$ C. Huisman, ${ }^{7}$ M. D. Hazenberg, ${ }^{7}$ J. J. de Soet, ${ }^{8}$ \\ J. de Lange, ${ }^{2}$ and F. R. Rozema ${ }^{1,2,9}$
}

${ }^{1}$ Department of Dental Medical Interaction, Academic Centre for Dentistry Amsterdam, University of Amsterdam and VU University, Gustav Mahlerlaan 3004, 1081 LA Amsterdam, The Netherlands

${ }^{2}$ Department of Oral- and Maxillofacial Surgery, Academic Medical Center, University of Amsterdam, Meibergdreef 9 , 1105 AZ Amsterdam, The Netherlands

${ }^{3}$ Department of Periodontology, Academic Centre for Dentistry Amsterdam, University of Amsterdam and VU University, Gustav Mahlerlaan 3004, 1081 LA Amsterdam, The Netherlands

${ }^{4}$ Department of Haemato-Oncology, University Hospital and Charles University Faculty of Medicine Plzen, Alej Svobody 80, 30460 Pilsen, Czech Republic

${ }^{5}$ Samuel Oschin Comprehensive Cancer Institute, Cedars-Sinai Medical Center, Los Angeles, CA, USA

${ }^{6}$ Department of Otolaryngology and Head and Neck Surgery, City of Hope National Medical Center, City of Hope, 1500 East Duarte Road, Duarte, CA, USA

${ }^{7}$ Department of Hematology, Academic Medical Center, University of Amsterdam, Meibergdreef 9, 1105 AZ Amsterdam, The Netherlands

${ }^{8}$ Department of Preventive Dentistry, Academic Centre for Dentistry Amsterdam, University of Amsterdam and VU University, Gustav Mahlerlaan 3004, 1081 LA Amsterdam, The Netherlands

${ }^{9}$ Department of Oral-and Maxillofacial Surgery, VU University Medical Center, VU University, De Boelelaan 1117, 1081 HZ Amsterdam, The Netherlands

Correspondence should be addressed to T. M. Haverman; thijs.haverman@acta.nl

Received 19 December 2013; Accepted 27 February 2014; Published 10 April 2014

Academic Editor: Vera L. Petricevich

Copyright (C) 2014 T. M. Haverman et al. This is an open access article distributed under the Creative Commons Attribution License, which permits unrestricted use, distribution, and reproduction in any medium, provided the original work is properly cited.

\begin{abstract}
Hematopoietic stem cell transplantation (HSCT) is widely used as a potentially curative treatment for patients with various hematological malignancies, bone marrow failure syndromes, and congenital immune deficiencies. The prevalence of oral complications in both autologous and allogeneic HSCT recipients remains high, despite advances in transplant medicine and in supportive care. Frequently encountered oral complications include mucositis, infections, oral dryness, taste changes, and graft versus host disease in allogeneic HSCT. Oral complications are associated with substantial morbidity and in some cases with increased mortality and may significantly affect quality of life, even many years after HSCT. Inflammatory processes are key in the pathobiology of most oral complications in HSCT recipients. This review article will discuss frequently encountered oral complications associated with HSCT focusing on the inflammatory pathways and inflammatory mediators involved in their pathogenesis.
\end{abstract}

\section{Introduction}

Hematopoietic stem cell transplantation (HSCT) is a potentially curative treatment for patients with various hematological malignancies, bone marrow failure syndromes, and congenital immune deficiencies. Stem cells can be obtained from bone marrow, peripheral blood, or umbilical cord blood. Autologous HSCT (in which stem cells are derived from the patient) is utilized to treat chemosensitive malignancies, such as multiple myeloma, non-Hodgkin, and Hodgkin lymphoma. Its anticancer effect is entirely derived from the high-dose, myeloablative conditioning regimen, whereas 
a subsequent autologous stem cell infusion enables bone marrow recovery. Allogeneic HSCT (in which the stem cells originate from a related or unrelated donor) is often the preferred treatment in a number of other hematological malignancies such as acute and chronic leukemia and relapsed lymphoma, because of its graft versus leukemia/lymphoma $(\mathrm{GvL})$ effect, which is an immunological response of donorderived immune cells against malignant cells. In the late 1990s, a better understanding of GvL biology led to preparative regimens that involve less intensive conditioning radiochemotherapy and are thus less directly toxic than myeloablative regimens. Unlike traditional myeloablative conditioning, these reduced intensity conditioning (RIC) regimens are primarily immunosuppressive to enable engraftment of the transplanted donor cells and depend on the graft to eradicate cancer. RIC transplants can also be conducted in patients previously not eligible for myeloablative protocols, because of older age or medical condition [1]. GvL responses are often accompanied by graft versus host disease (GvHD), a complication of allogeneic HSCT in which donor-derived immune cells including T-, B-, and Natural Killer (NK) cells raise an immune response against normal host tissue, such as the oropharynx, gut, skin, eyes, and liver.

The overall prevalence of oral complications in patients receiving HSCT is estimated to be $80 \%$ [2]. Frequently encountered acute oral complications include mucositis, local and systemic infections, oral dryness, and taste changes [3-6]. Whereas in autologous HSCT most of these problems have resolved after 6 months, patients that have been treated with allogeneic HSCT may also later on experience complications associated with GvHD.

Inflammatory processes are the key in the pathobiology of most oral complications in HSCT recipients. This review article will discuss frequently encountered oral complications associated with HSCT focusing on the inflammatory pathways and inflammatory mediators involved in their pathogenesis.

\section{Oral Mucositis}

Oral mucositis (OM) is an inflammatory-driven process of the oral mucosa and is one of the best-studied oral side effects of cancer therapy. It is induced by radiation therapy and/or chemotherapy and is characterized clinically by mucosal damage ranging from mild inflammation presenting as erythematous atrophic lesions to extensive ulcerations penetrating the submucosa. In HSCT recipients, mucositis is not limited to the oral cavity but may occur along the entire orodigestive tract. The mechanisms underpinning the pathobiology of mucositis are thought to be largely the same regardless of the location along this tract.

The incidence of $\mathrm{OM}$ has been estimated to range from $75 \%$ to $100 \%$ following myeloablative conditioning regimens [7] and has been reported as the most painful and debilitating oral complication, significantly impairing quality of life (QoL) [8]. Prospective studies reported that conditioning regimens containing high-dose melphalan, busulphan, and cyclophosphamide in combination with total body irradiation (TBI) were associated with severe OM [9-11].
While OM risk among patients receiving conditioning regimens including TBI exceeds $90 \%$, the risk drops to $30 \%-50 \%$ for individuals being treated with protocols without TBI [12]. Conditioning regimens are the most important parameters determining OM risk, but patient-related factors are also involved, although the association is less clear. In particular the local tissue environment and mucosal responses to damaging stimuli, which may in part be genetically determined, govern the risk, course, and severity of mucosal injury $[12,13]$. Genetic determinants of OM risk include genes that regulate the availability of active chemotherapy drug metabolites. For example, evaluation of genetic variation in folate-metabolizing enzymes may help to identify patients at greater risk for methotrexate toxicity, but enzyme deficiencies may be relatively rare [11]. In contrast, differences in the expression of genes associated with biological pathways that drive mucositis are more common. For instance, genetic polymorphisms associated with the expression of inflammatory mediators such as tumor necrosis factor- (TNF-) $\alpha$ have been implicated in OM risk in patients undergoing allogeneic HSCT [14]. Recently, Sonis et al. identified a singlenucleotide polymorphisms- (SNP-) based Bayesian network developed from saliva-sourced DNA that may predict an individual's risk to develop severe OM following conditioning for autologous HSCT [12].

OM following RIC regimens is usually less severe and of shorter duration $[15,16]$. However, RIC regimens may vary considerably in intensity and accompanying toxicity and more prospective studies are necessary.

Considerable progress has been made in the past years in understanding the pathobiology of mucositis [17-19] and we will summarize recent insights.

2.1. Pathobiology of Mucositis. Historically, OM was viewed solely as an epithelium-mediated event that was the result of nonspecific toxic effects of radiation and/or chemotherapy on rapidly proliferating basal epithelial cells resulting in clonogenic cell death. This continues to be a component of a much more complex contemporary model of mucositis developed by Sonis [19]. This five-phase biological model describes a cascade of interrelated and overlapping genetic and histopathological events. These phases include initiation, upregulation/activation, signal amplification, ulceration, and healing involving epithelial and connective tissues of the mucosa (Figure 1).

The initiation phase in the pathobiology of mucositis is characterized by radio- and/or chemotherapy-induced DNA and non-DNA damage that results in injury of basal epithelial cells, submucosal cells, and endothelial cells. In particular submucosal cell death contributes to injury [20]. In response to this damage, reactive oxygen species (ROS) are generated, which amplify DNA damage and clonogenic cell death and activate in the subsequent phase a number of transcription factors, including nuclear factor- (NF-) $\kappa \mathrm{B}[7,21]$.

$\mathrm{NF}-\kappa \mathrm{B}$ is considered as the "gatekeeper" for various inflammatory pathways involved in mucositis [18]. Activation of NF- $\kappa \mathrm{B}$ occurs in virtually all epithelial and submucosal cells and induces expression of adhesion molecules and 


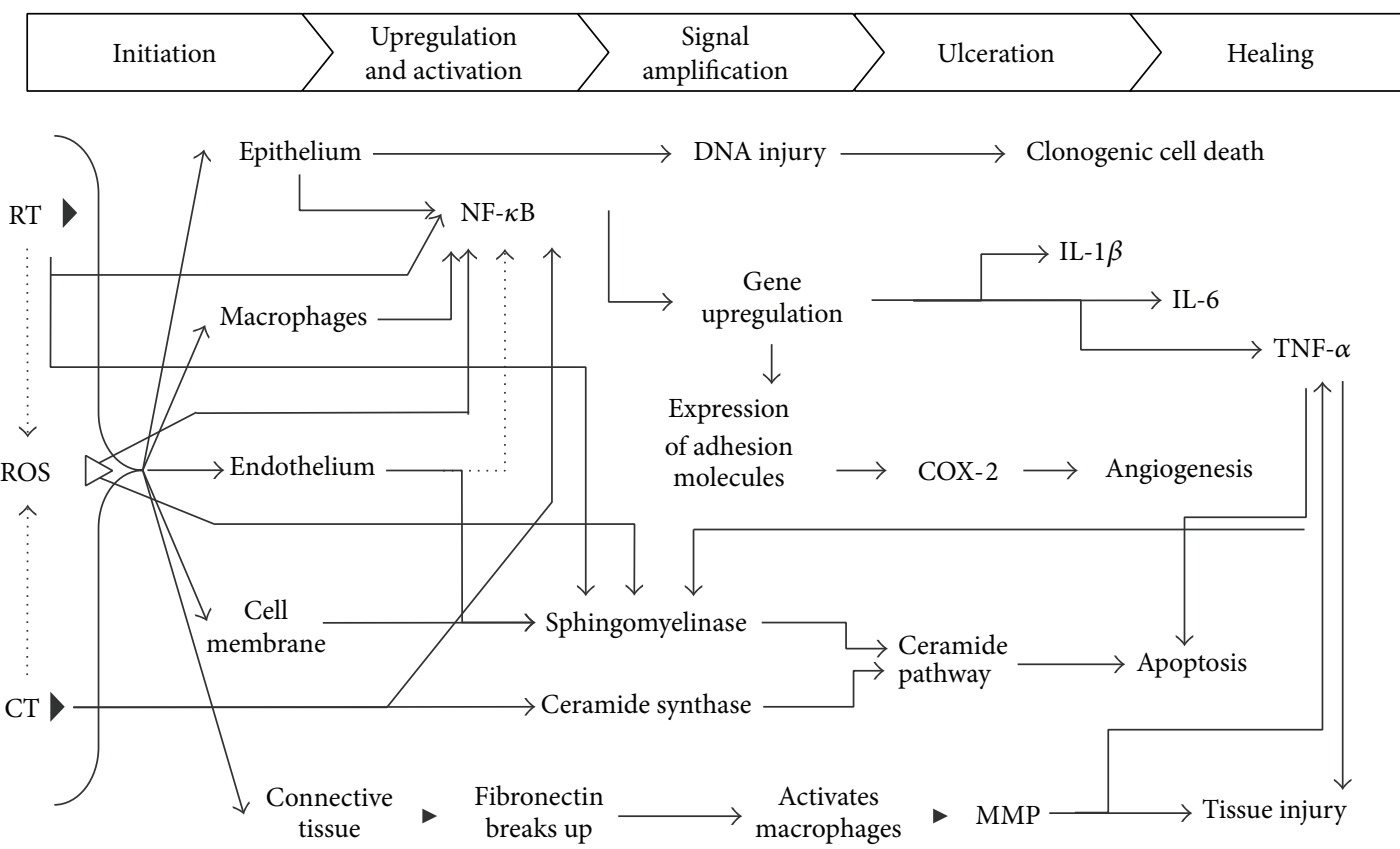

FIGURE 1: An overview of the pathogenesis of oral mucositis. RT: radiotherapy, ROS: reactive oxygen species, CT: chemotherapy, NF- $\kappa$ B: nuclear factor-kappa B, IL: interleukin, TNF- $\alpha$ : tumor necrosis factor-alpha, COX-2: cyclooxygenase-2, and MMP: matrix metalloproteinase. Courtesy of Professor ST Sonis and the Multinational Association of Supportive Care in Cancer (MASCC).

activation of the mitogen-activated protein kinase (MAPK) and cyclooxygenase- (COX-) 2 pathways [19, 21, 22]. Furthermore, the finding that NF- $\kappa \mathrm{B}$ activation can have both proapoptotic and antiapoptotic effects (through apoptosis regulator BcL-2 genes) makes it a significant factor in determining the fate of normal tissues following cytotoxic therapy [22].

Upregulation of NF- $\kappa \mathrm{B}$ generates the formation of interleukin- (IL-) $1 \beta$, IL-6, and TNF- $\alpha$ [23]. These proinflammatory mediators stimulate additional injury through positive feedback loops (signal amplification phase), whereby TNF- $\alpha$ acts on pathways to reinforce NF- $\kappa$ B activation. Additional support for the role of cytokines has been provided by therapies that interfere with the development of mucositis by influencing the cytokine profile [24-31].

Together with alternative, NF- $\kappa \mathrm{B}$ independent pathways such as the ceramide pathway, this results in apoptosis of submucosal and basal epithelial cells leading to mucosal ulceration.

Furthermore, metalloproteinases (MMPs) are involved in the pathobiology of mucositis $[32,33]$. Damage to the submucosa is, besides from being a direct effect of radiation or chemotherapy, mediated by the activation of Activating Protein-1 (AP-1), which stimulates the secretion of MMPs by fibroblasts $[19,34]$. TNF- $\alpha$ is an important regulator of the transcriptional activity of AP-1, by initiating the MAPK signaling pathway activating c-JUN amino-terminal kinase [32]. Moreover, IL- $1 \beta$ and COX- 2 may induce MMP activation [19]. Increased levels of MMP-2, -3, -9, and -12 are associated with inflammatory infiltrates and maximum tissue damage. In contrast, MMP-1 expression correlates with tissue restitution [32]. No significant correlation was found between levels of MMP-1, MMP-8 (neutrophil collagenase), and MMP-13 (involved in degradation of extracellular matrix (ECM) and bone) in oral rinsing samples and OM scores in allogeneic HSCT recipients [35].

The ulcerative phase comprises loss of mucosal integrity and microbiological colonization with subsequent further proinflammatory cytokine production.

Healing of the oral mucosa has received limited study. It is associated with epithelial proliferation, often concurrent with hematopoietic recovery, reestablishment of local microbial flora, and absence of factors that interfere with wound healing such as infection and mechanical irritation [36]. The ECM plays a significant role in signaling between tissues and is a complex structural network of fibrous proteins, proteoglycans, and glycoproteins. ECM stimulates epithelial cell migration, proliferation, and differentiation, leading to renewal of the mucosa [19]. Epidermal growth factor (EGF), transforming growth factor- (TGF-) $\alpha$, IL-1, and interferon(IFN-) $\gamma$ appear to promote this process by upregulating TGF$\beta$, which stimulate expression of fibronectin and collagen type IV [37]. After healing, the oral mucosa appears normal, but appearances may be deceptive as ongoing angiogenesis and connective tissue maturation result in increased risk for OM if additional cytotoxic therapy is administered [7].

2.2. Modifying Factors. Several anti-inflammatory cytokines and growth factors have been identified to have a protective effect. De Koning et al. [38] suggested a protective role of IL10 , after observing more severe intestinal damage following 
methotrexate treatment in IL-10 deficient mice compared to wild-type controls. Several animal studies indicated that IL11 , an inhibitor and downregulator of inflammatory mediators including nitric oxide (NO), reduces OM [39]. Moreover, it was suggested that subcutaneous administration of IL-11 reduced the severity of OM by maintaining keratin production in epithelial cells, as well as by reducing mucosal proinflammatory cytokine expression [23]. Unfortunately, IL-11 administration caused severe fluid retention and early mortality in a clinical trial, leading to early closure of the study [40]. Topical TGF- $\beta 3$ prior to chemotherapy administration negatively regulated epithelial cell proliferation and reduced OM in a hamster model [41]. Keratinocyte growth factor-1 (KGF-1) has pleiotropic activity. It is mitogenic and promotes cell survival by upregulating BcL-2 genes, which suppress apoptosis [42]. KGF-1 also activates nuclear factor erythroid 2-related factor 2 (Nrf2) that coordinates the expression of cytoprotective genes and upregulates IL13 , an anti-inflammatory cytokine that attenuates the effects of TNF- $\alpha$ [37]. Human recombinant KGF-1 has been found beneficial for the prevention of OM in patients treated with high-dose CT and TBI followed by autologous HSCT [31, 43].

An important mediator of local inflammatory responses is the oral and intestinal microbiome. It has been demonstrated in mice that perturbations of local immune responses to the microbiota can lead to spontaneous inflammation, and vice versa, and loss of microbial diversity is associated with a proinflammatory state $[44,45]$. Shifts in the commensal oral bacterial flora associated with leukemia, neutropenia, direct effects from anticancer therapy, antibiotic use, hyposalivation, and mucosal surface changes are well documented $[46,47]$. For example, results from a study in breast cancer patients suggested a shift to a more complex oral bacterial profile following chemotherapy [48], and a recent study using $16 \mathrm{~S}$ rRNA and 454 pyrosequencing suggested that chemotherapy-induced changes of the bacterial composition were predictive for OM risk [49]. Certain bacteria may be actively involved in oral mucositis. In HSCT recipients, substitution with coagulase-negative staphylococci (CONS) for streptococci was associated with OM [50]. The presence of Porphyromonas gingivalis, a strictly anaerobic Gram-negative microorganism associated with periodontitis, was shown to have a positive predictive value for mucosal ulcerations in HSCT patients [51]. It was suggested that $P$. gingivalis plays a role in the initiation of $\mathrm{OM}$ by upregulating Toll-Like Receptors (TLRs), which facilitate NF- $\kappa \mathrm{B}$ activation.

Salivary defense proteins and peptides are important determinants of the environment of oral tissues. Their effects are synergistic and in many cases reinforced by immune and/or inflammatory reactions of the oral mucosa. Some defense proteins, like salivary immunoglobulins and heat shock proteins, are involved in both innate and acquired immunity. Cationic peptides and other defense proteins (e.g., lysozyme, bactericidal permeability increasing protein (BPI) salivary amylase, cystatins, proline-rich proteins, mucins, peroxidases, and statherin) are primarily involved in innate immunity [52]. However, the role of saliva in the development of $\mathrm{OM}$ is presently unclear $[53,54]$.
2.3. Infectious and Inflammatory Complications of Oral Mucositis. Once ulcerations are manifest, they represent a risk for systemic infection with bacteremia, fungemia, fever, and sepsis, particularly with concomitant neutropenia $[7,55-57]$. The damaged mucosa may provide a portal of entry for microorganisms and inflammatory products into the bloodstream [58-60]. OM is the most likely origin of bacteremia with oral viridans streptococci most frequently resulting in fever and may lead to acute respiratory distress syndrome and septic shock [61, 62]. Bacteremia may also be caused by coagulase-negative staphylococci (CONS) originating from the oral mucosa [50,63]. It should be noted, however, that, in only $30 \%$ of patients with mucositis and fever, a bacterial cause could be identified. Mucosal barrier injury likely triggers a systemic inflammatory response, and this response by itself may cause neutropenic fever [57]. Infectious and inflammatory complications associated with ulcerative $\mathrm{OM}$ may explain the observation reported in a number of studies that $\mathrm{OM}$ is associated with an increased risk to early nontumor-related mortality in HSCT recipients $[6,64,65]$.

As described below tissue damage associated with mucositis is also thought to be involved in the pathogenesis of GvHD [66, 67]. However, Vokurka et al., [68] found no evidence for this notion in a study in which OM was prevented by oral cryotherapy in allogeneic HSCT recipients treated with high-dose melphalan conditioning regimens [68].

\section{Graft versus Host Disease}

In allogeneic HSCT recipients, GvHD is frequently encountered and remains a major cause of morbidity and mortality. Organs most at risk to be affected by this complex immunologic disorder include the skin, gastrointestinal tract including the oropharynx and liver, and eyes. Billingham [69] described three fundamental elements required for the occurrence of GvHD. (i) The graft must contain immunologically competent cells ( $\mathrm{T}$ cells); (ii) the recipient must be incapable of rejecting the graft cells; and (iii) the recipient must express tissue antigens that are not present in the donor $[66,70]$. The most important genetically defined proteins on host cells to which donor $\mathrm{T}$ cells respond are human leukocyte antigens (HLA). The degree of HLA match of donor to patient is the most important risk factor for GvHD. Additional risk factors include minor histocompatibility antigens (mHA), older age of patient, primary disease, graft source, donor parity and sex mismatch, the toxicity of conditioning regimens, and the effectiveness of GvHD prophylaxis [71, 72]. Once established, GvHD is difficult to treat. As GvHD and GvL responses usually come together, a too rigorous GvHD prophylaxis or treatment may carry the cost of increased risk of disease relapse [73]. GvHD can be classified as either acute GvHD (aGvHD) or chronic GvHD (cGvHD), defined by clinical and pathologic features $[74,75]$.

3.1. Acute Oral GvHD. Oral aGvHD is characterized by mucosal erythema and inflammation, atrophy, and ulcerations. It may be also associated with hyperkeratosis and 
fibrosis. Salivary gland function and taste may be impaired [76].

In rare cases, hyperacute oral aGvHD may develop as early as one to two weeks after HSCT, but the differential diagnosis of aGvHD, OM, and infection can be challenging [77]. Oral aGvHD should be considered when infection has been excluded and ulcerations fail to heal with hematologic recovery 21 to 28 days after allogeneic HSCT.

The exact incidence of oral aGvHD is not known. The condition is potentially underrecognized, but it is estimated that between $35 \%$ and $60 \%$ of patients with aGvHD have oral manifestations [76]. A pilot study reported that patients undergoing RIC HSCT developed less oral aGvHD than recipients of myeloablative allogeneic HSCT [78]. A recent observational study in allogeneic HSCT following RIC conditioning reported an incidence of oral aGvHD of 7\% [79].

3.2. Chronic Oral $c G v H D$. cGvHD occurs in $40-70 \%$ of allogeneic HSCT survivors. The most common sites involved at the initial diagnosis of cGvHD are skin (75\%), mouth (51\%$63 \%)$, liver (29\%-51\%), and eye (22\%-33\%) [80].

However, the oral cavity may be the principal and sometimes the only site of involvement [77] and can serve as a useful component of cGvHD diagnosis and staging [75]. Oral cGvHD may affect the mucosa and/or the salivary glands and may develop into mucosal sclerosis. Oral cGvHD as well as its management is associated with increased infection risk [81]. Although oral cGvHD is mild in the majority of patients, it should always be considered as clinically significant due to its often prolonged duration. In a subset of patients it is a continuous source of pain, impairing oral function, affecting alimentation and nutritional status, impeding the maintenance of oral health, and reducing quality of life [82, 83]. In a cohort of RIC HSCT recipients, cGvHD-related oral symptoms developed with a median onset of seven months after transplant persisted for a median duration of six months and reoccurred in one-third of affected patients [79].

3.3. Oral Mucosal $c G v H D$. Chronic mucosal GvHD of the oropharynx is estimated to occur in $45-83 \%$ of patients $[76,84]$ and is characterized by lichenoid inflammation particularly affecting the tongue, buccal mucosa, and the lips [85] (Figure 2). Clinical signs resemble those seen in lichen planus and include white hyperkeratotic reticulations and plaques, erythema, and ulcerations, which may be covered with a pseudomembrane. In addition, the gingiva may become atrophic. Early clinical recognition and treatment of GvHD prevent progression into more significant morphological changes [79]. Typical histopathological features include apoptotic bodies, satellite necrosis and lichenoid interface inflammation, and lymphocytic infiltration at the junction of the epithelium and subepithelial connective tissue $[74,79]$. Additionally, an inflammatory infiltrate caused by superimposed infection may be present. It is important to be aware of other complications that can mimic oral cGvHD, including oral mucosal reactions to medications (including mammalian target of rapamycin (mTOR) inhibitors), local allergic reactions, infections, and second primary tumors.

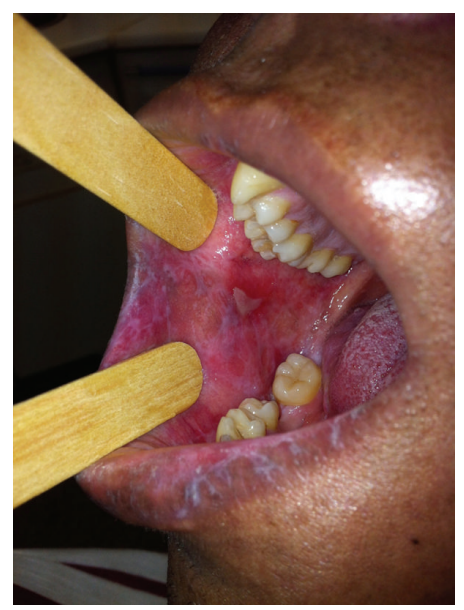

FIgURE 2: Chronic mucosal GvHD characterized by lichenoid inflammation and pseudomembranous mucositis. Courtesy of Dr. Maria Elvira Correa.

3.4. Salivary Gland $c G v H D$. Salivary gland dysfunction is common in HSCT patients and is related to the conditioning regimen, dehydration, medication, and cGvHD.

The primary symptom of salivary gland cGvHD is xerostomia (subjective complaint of oral dryness), but patients may also describe oral sensitivity and burning [81]. cGvHD of the salivary glands is probably underdiagnosed. Some patients experience xerostomia induced by HSCT conditioning (particularly by TBI-containing regimens) and anticholinergic medications, and this may persist through the period when salivary gland cGvHD develops, making onset and diagnosis less evident [86]. Salivary gland cGvHD mimics Sjögren's syndrome, which is commonly associated with xerophthalmia and may also relate to pulmonary GvHD involvement [86]. Saliva plays a critical role in mastication and swallowing, taste, speech, tooth remineralization, the maintenance of oral $\mathrm{pH}$ balance, and prevention of oral infections [87].

Patients with salivary gland cGvHD are at risk of developing complications because of diminished salivary defense mechanisms, including antifungal and anticariogenic activities $[88,89]$. Castellarin and coworkers reported cGvHDassociated rapidly progressive dental caries with cervical and interproximal involvement [90]. Measurement of resting and stimulated whole-saliva flow rates, individual analysis of the risk of oral diseases, and preventive measures should be part of supportive care in these patients [89].

Another complication of salivary gland cGvHD is the formation of mucoceles. Mucoceles are subepithelial extravasations of sialomucin that occur at the epithelial-connective tissue interface around the obstructed duct of minor salivary glands [74]. Clinically it presents as a soft, fluid-filled elevation of the epithelium $[75,91]$.

3.5. Sclerotic Alterations. Oral sclerotic involvement resulting in limited jaw opening can be the result of perioral and facial skin sclerosis, typically as an extension of generalized sclerotic changes. Facial changes associated with Cushing's 
syndrome may contribute to reduced jaw opening. Mucosal sclerosis is rare but may develop as a complication of longstanding severe ulcerative mucosal cGvHD [81]. It may restrict jaw opening and tongue movement and may extend to the throat and esophagus resulting in dysphagia. It can be associated with pain and secondary ulceration, significantly impairing alimentation and performing oral hygiene measures [81].

3.6. Pathophysiology of Acute and Chronic Oral GvHD. Development of aGvHD occurs in three overlapping and interrelated steps: (i) conditioning; (ii) activation and expansion of alloreactive cells; and (iii) the effector phase [74, 92].

First, conditioning regimens induce tissue damage (e.g., mucositis and skin damage), inducing the release of adenosine triphosphate (ATP) and other damage signals leading to secretion of TNF- $\alpha$, IL-1, IL- 6 , chemokines, and adhesion factors [93]. This will promote activation and proliferation of host antigen presenting cells (APCs), increased expression of costimulatory molecules, and migration of APCs to secondary lymphoid organs. The impact of the microbiota on GvHD has been recognized to be significant as it has been postulated that the intestinal microflora and endotoxin exert a crucial step in APC activation [94]. Translocation of bacteria and bacterial components through damaged epithelial barriers triggers additional production of inflammatory cytokines, particularly TNF- $\alpha$, IL-1, and IL-12 [66]. A strong correlation between increased TNF- $\alpha$ serum levels and aGvHD has been described [95-98]. In reverse, inflammation secondary to GvHD was reported to be associated with major shifts in the composition of the intestinal microbiota, which may aggravate the severity of inflammation [99]. Whether interactions between the oral microbiota and host defense mechanisms may contribute to the pathobiology of oral GvHD remains to be assessed.

During the second phase activated host APCs encounter resting donor $\mathrm{T}$ cells and present host antigens to these cells, which become activated, proliferate, and express effector cytokines [100]. Following activation, T cells exit the lymphoid organs, enter the blood circulation, and subsequently migrate to the host target tissues (e.g., skin, orodigestive tract, and liver) [92].

In the third (effector) phase, a complex cascade of cellular mediators and inflammatory agents induce and amplify tissue damage $[66,70]$. Donor T cells cause tissue damage via direct cytotoxicity against epithelial cells and release of interferon(IFN-) $\gamma$ and IL-2 [74]. This activates NK cells and resident macrophages that release proinflammatory cytokines including TNF- $\alpha$, IL-1, and IL-6 leading to amplification of the proinflammatory cytokine cascade ("cytokine storm") that is a hallmark of acute GvHD [101-103].

A recent study presented an association between IL1B polymorphisms and aGvHD, as well as between IL-1 $\beta$ levels, in both saliva and blood, and aGvHD development. In addition, an association was found between the CC genotype and high levels of IL-1 $\beta$ suggesting that assessing the kinetics of IL-1 $\beta$ in both fluid types may be useful for monitoring the progression of the disease [104].
Selected cytokines involved in GvHD are summarized in Table 1.

CD4+ cells effector function is primarily mediated through secretion of cytokines. Depending on the conditions of activation and subsequent cytokine profile, CD4+ cells can be subdivided into Th1, Th2, Th17, and other subtypes [126]. Although oversimplified, Th1, Th2, and Th17 can be characterized by secretion of IFN- $\gamma$, IL-4, and IL-17, respectively [127]. Activation of CD8+ cytotoxic T cells is accompanied by increased production of effector molecules, which perpetuate the damage. Both Fas/FasL-dependent and perforin/granzyme-dependent apoptosis are important in GvHD-induced tissue damage [74]. Traditionally, aGvHD is considered to be driven by Thl cytokines and mediated by CD8+ effectors [70]. However, the pathobiology appears far more complex and B cells may also play a role in the development of aGvHD [128].

Our understanding of cGvHD is limited, partly because of the difficulty with generating animal models that are true representatives of clinical disease. Two theories evolved regarding the pathogenesis of $\mathrm{cGvHD}$. The first theory is end-stage alloreactivity, in which donor T cells augment a Th2 immune response [129]. The second theory postulates that $c G v H D$ is due to poor immunologic recovery with the development of autoreactive $\mathrm{T}$ lymphocytes due to lack of thymic control or peripheral mechanisms of deletion [70].

Likely, the pathogenesis of cGvHD begins with uncontrolled expansion of donor T cells in response to both alloand autoantigens. The activated $\mathrm{T}$ cells will subsequently cause target organ damage by inflammatory cytokines, cytolytic attack, and fibrosis and/or by promoting B-cell activation and production of autoantibodies [130]. Evidence exists that B-cell deregulation and the expansion of host B cells [131] contribute to cGvHD. Miklos et al. [132] demonstrated that the presence of antibodies directed to $\mathrm{H}-\mathrm{Y}$ proteins (a transplantation antigen that can lead to rejection of male grafts by female recipients) correlates with cGvHD. Also, elevated levels of B-cell activating factor (BAFF) contribute to B-cell activation in patients with active cGvHD [133]. Furthermore, Young et al. [134] described that donor $\mathrm{B}$ cells are activated by donor CD4+ T cells to upregulate MHC II and costimulatory molecules. Acting as efficient APCs, activated donor B cells enhance donor CD4+ T clonal expansion, thereby augmenting the capacity of these cells to induce autoimmune-like cGvHD.

Indeed, comparable to autoimmune diseases, both $\mathrm{T}$ - and B-cell responses appear to play a role in the pathogenesis of $\mathrm{cGvHD}$, suggesting that this reflects a general loss of tolerance including abnormalities in the function of regulatory (Treg) cells. Tregs limit the ability of the immune system to adapt to an inflammatory environment [135]. Impairment of Tregs is associated with loss of peripheral tolerance and with development of cGvHD [136].

Acute GvHD has long been conceived to be dependent upon type I cytokine-driven CD8 effectors, whereas cGvHD has been associated with type II CD4 $\mathrm{T}$ cells and Th2 cytokines (IL-4 and IL-10) are considered to be the predominant cytokines in the pathobiology of cGvHD [137]. However, the mechanisms are far more complex, as both aGvHD and 
TABLE 1: Selected inflammatory cytokines involved in graft versus host disease; intervention in cytokine production is an obvious approach to ameliorate GvHD, but because cytokines have complex and pleomorphic effects, this may result in unintended consequences.

\begin{tabular}{|c|c|c|}
\hline Cytokine & Main role in GvHD & References \\
\hline TNF- $\alpha$ & $\begin{array}{l}\text { Activates APCs and enhances alloantigen presentation, recruits effector cells to target organs mediated by } \\
\text { inflammatory chemokines and directly causes tissue necrosis. }\end{array}$ & {$[66,105-107]$} \\
\hline IL- $1 \alpha$ & Higher salivary IL- $1 \alpha$ is associated with oral dryness in oral cGvHD. & {$[108]$} \\
\hline IL-1 $\beta$ & $\begin{array}{l}\text { Primary activator of chemotactic cytokines and expression of adhesion molecules that facilitate the } \\
\text { migration of leucocytes into tissues. }\end{array}$ & {$[66,109]$} \\
\hline IL-6 & $\begin{array}{l}\text { Key factor in CD } 4+\text { T cell-dependentaGvHD and inhibition of Tregs. Moreover, an association between } \\
\text { IL- } 6 \text { and the severity of oral cGvHD has been reported. }\end{array}$ & {$[108,110,111]$} \\
\hline IL-2 & Critical for T-cell differentiation. & {$[98]$} \\
\hline IL-15 & $\begin{array}{l}\text { IL-2-like cytokine, enhances T-cell and NK cell proliferation and improves immune reconstitution after } \\
\text { allogeneic HSCT. }\end{array}$ & {$[98]$} \\
\hline IL-12 & $\begin{array}{l}\text { Pro-inflammatory cytokine involved in the activation of donor T cells. Stimulates T cell and NK cell } \\
\text { proliferation and induces maturation of Thl cells. }\end{array}$ & {$[98]$} \\
\hline IFN- $\gamma$ & $\begin{array}{l}\text { Complex role in innate and adaptive immune responses. IFN- } \gamma \text { is able to increase chemokine receptors, } \\
\text { MHC proteins and adhesions molecules. Renders monocytes and macrophages more sensitive to LPS } \\
\text { stimulation, and amplifies GvHD by direct damage to epithelial cells and by NO-mediated } \\
\text { immunosuppression. May just reflect the presence of large numbers of activated T cells, and does not } \\
\text { necessarily imply a role of this cytokine in the pathogenesis of GvHD. }\end{array}$ & {$[66,112]$} \\
\hline IL-17 & $\begin{array}{l}\text { IL-17 is mainly produced by activated Th-17 cells, stimulates IL- } 6 \text { and IL- } 8 \text { secretion and enhances the } \\
\text { expression of adhesion molecules. May play a role in either triggering or aggravating aGvHD and cGvHD, } \\
\text { but detailed role remains to be elucidated. }\end{array}$ & [113-115] \\
\hline IL-18 & $\begin{array}{l}\text { Affects both Th1 and Th2 mediated responses and is elevated in aGvHD. In mouse models, administration } \\
\text { of IL-18 early after allogeneic HSCT attenuated aGvHD by decreasing Th1 cytokine production. }\end{array}$ & {$[98]$} \\
\hline IL-5 & $\begin{array}{l}\text { Produced by T cells, mast cells and eosinophils has been associated with aGvHD. Stimulates B cell growth } \\
\text { and increases immunoglobulin secretion; is a key mediator in eosinophil activation. }\end{array}$ & {$[98,116]$} \\
\hline IL-10 & $\begin{array}{l}\text { Inhibits secretion of IL-1, TNF, IL-6, IL- } 8 \text { and IL- } 12 \text { from monocytes/macrophages and secretion of IFN- } \gamma \\
\text { and IL- } 2 \text { by T-cells. A protective role for donor-derived IL-10 has been suggested in aGvHD, as it decreases } \\
\text { apoptosis. High concentrations of IL-10 in aGvHD may reflect systemic infection and may contribute to } \\
\text { immunodeficiency. }\end{array}$ & {$[98,117-120]$} \\
\hline IL-21 & $\begin{array}{l}\text { IL-21 enhances Th1 and Th17 differentiation while inhibiting the conversion of inducible Tregs from naive } \\
\text { T cells. }\end{array}$ & {$[121]$} \\
\hline IL-22 & $\begin{array}{l}\text { Structurally related to IL-10 and is secreted by Th17 cells and innate immune cells. In line with these } \\
\text { findings, IL-22 may act as a protective regulator of tissue sensitivity to GvHD. }\end{array}$ & {$[122,123]$} \\
\hline IL-7 & Is associated with the development of aGvHD, but mechanism is not well understood. & {$[98,124,125]$} \\
\hline
\end{tabular}

cGvHD are initially characterized by increased Th2 cytokines production [138]. Studies have also shown decreased Th2type cytokine levels among patients who developed cGvHD compared with those who did not $[139,140]$. Taken together, evidence of Th2 involvement in cGvHD is limited and, depending upon the animal model used, all 3 major subtypes of CD4 cells (Th1, Th2, and Th17) have been implicated in cGvHD [141].

Imanguli and coworkers systematically examined oral mucosal biopsies and assessed that the clinical severity of oral cGvHD was correlated with the presence of apoptotic epithelial cells. These cells were often found adjacent to infiltrating effector-memory T cells, expressing markers of cytotoxicity and type I cytokine polarization (T-bet+ $\mathrm{T}$ cells) [142]. Accumulation of T-bet+ T-cell effectors was associated with increased proliferation and the expression of the type I chemokine receptor CXCR3. In both infiltrating cells and keratinocytes, increased expression of the CXCR3 ligand MIG (CXCL9) and IL-15, IFN-inducible factors, type I differentiation, and expansion of alloreactive effectors was observed [142]. These findings also challenge the current paradigm of cGvHD as a Th2 driven disorder.

Salivary gland cGvHD is characterized by typical histopathological changes (Figure 3 ) including periductal mononuclear infiltration particularly of CD45, CD45RO, CD4 and CD8 positive cells, atrophy of salivary gland lobules, and periglandular fibrosis $[86,143,144]$.

\section{Infections}

Infections, including those from oral sources, are a frequent complication of HSCT [70, 76, 92]. Risk factors for 


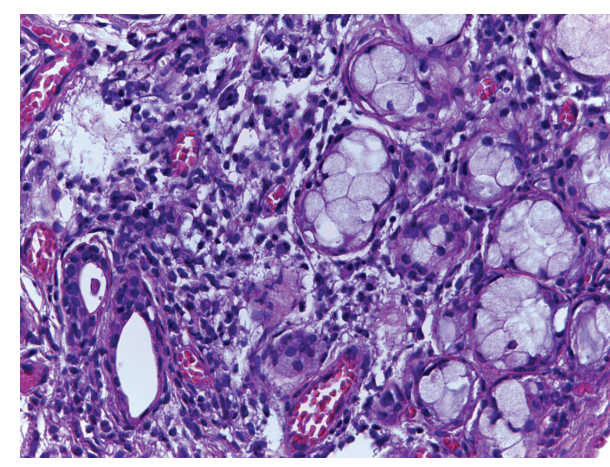

(a)

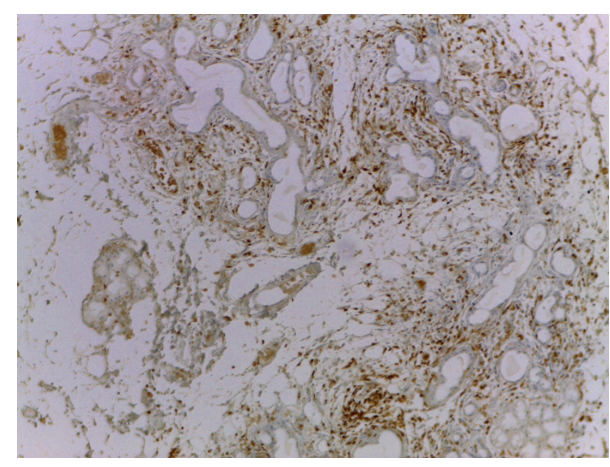

(b)

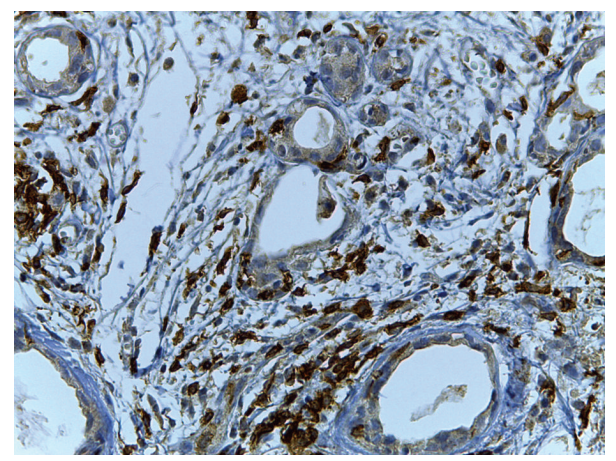

(c)

FIGURE 3: Typical histopathological changes of salivary gland in chronic GvHD. Periductal lymphocytic infiltrate and lymphocyte exocytosis can be noted implying high inflammatory activity. (a) Hematoxylin and eosin stained histological section (original magnification $\times 400$ ); (b) immunostained section targeting for CD45 (original magnification $\times 100$ ); (c) immunostained section targeting for CD8. Lymphocytes are shown within ductal epithelium and acinar unit (original magnification $\times 400$ ). Courtesy of Drs. Tânia C Benetti Soares and Maria Elvira Correa.

obtaining infections include the underlying malignant disease, the medical condition and comorbidities, the presence of chronic or latent infections, the type of transplant, the source of stem cells, the use of antimicrobials, mucosal barrier loss, immunosuppression and myelosuppression induced by HSCT conditioning, and GvHD and/or GvHD management [145]. Two mechanisms play a major role in infection risk. One depends on nonspecific defenses such as the integrity of surface barriers and presence of systemic or salivary antimicrobial agents, such as defensins [146]. The other major defense against infections is the immune system, of which virtually all components are deficient after HSCT or suppressed by immunosuppressive therapy to prevent GvHD.

Uncomplicated recovery starts with healing of the mucosal tissues and recovery of granulocytes and NK cells about two weeks after myeloablative conditioning. However, T-cell and B-cell immune responses against viral, bacterial, and fungal organisms may be suppressed for a prolonged period of time, particularly in the setting of GvHD. This all results in disturbed homeostasis of the oral cavity and increased infection risk [71].

Oral infections may be associated with a wide variety of microorganisms, including bacteria, fungi, and viruses, virtually all of which may give rise to systemic infectious complications in the transplant population. The time of occurrence and appearance of the lesions may contribute to the differential diagnosis [145]. However, coexistent oral conditions such as $\mathrm{OM}$ and GvHD often complicate adequate and prompt diagnosis of opportunistic infections.

4.1. Bacterial Infections. As described previously, the oral bacterial flora changes before and following chemotherapy [48]. In a cohort of 37 allogeneic HSCT recipients a significant increase of oral colonization with potentially pathogenic microorganisms (predominantly Enterococcus faecalis and Candida spp.) was observed over the course of hospitalization [147].

It is important to be aware of modified clinical symptomatology of bacterial infections during the neutropenic phase of HSCT. Erythema, pain, edema, and fever may be the only clinical signs of an otherwise purulent infection.

$\mathrm{OM}$ is acknowledged to be the principal risk factor for bacteremia due to oral viridans streptococci (OVS) [148], but bacteremia with CONS may also originate from the oral cavity [63].

In addition to infections related to the oral mucosa, chronic infections associated with the dentition may give rise to complications. These infections typically involve the periapical area, impacted teeth, and the periodontium [149]. Periodontal infections, in particular, may represent an easily 
overlooked source of bacteremia and systemic infection in neutropenic patients $[150,151]$. Periodontal infection and inflammation may contribute to the risk of developing OVS and CONS bacteremia during neutropenia following HSCT [151]. Moreover, the reported positive association between $P$. gingivalis and $\mathrm{OM}$ suggests at least a mucosal reaction to this bacterial challenge [51]. There is anecdotal evidence that dental infection and inflammation also contribute to oral GvHD.

4.2. Fungal Infections. Candidiasis is typically caused by opportunistic overgrowth of C. albicans, a commensal oral yeast. It may be associated with a dry mouth, taste disturbances [152], and mucosal discomfort [153, 154]. Several variables contribute to its clinical expression, including immunosuppression, mucosal injury, and salivary dysfunction. In addition, antibiotics may alter the oral flora, thereby creating a favorable environment for fungal overgrowth [155]. The most common forms of intraoral candidiasis reported in oncology patients are pseudomembranous and erythematous candidiasis [156].

Current prophylactic strategies have reduced systemic candidiasis, although oropharyngeal and esophageal infections remain a common complication with potentially serious consequences.

It has been recognized that different Candida species provoke different immunologic reactions, making some strains more virulent than others [157]. During oral infection with Candida, a large number of proinflammatory and immunoregulatory cytokines are generated in the oral mucosa [158]. Villar et al. [159] demonstrated that highly invasive strains of $C$. albicans triggered higher levels of proinflammatory cytokines, including IL- $1 \alpha$, IL-6, IL-8, and TNF- $\alpha$ in epithelial cells and IL-6, IL-8, monocyte chemotactic protein- (MCP-) 1, MCP-2, and granulocyte colonystimulating factor (GCSF) in endothelial cells. C. glabrata was associated with oral ulcerations in HSCT recipients, as described by Laheij et al. [51]. Laheij et al. also identified $C$. $k e f y r$ as having a positive predictive value for mucosal ulcerations, but its prevalence is unknown in larger populations. Chen et al. [160] and de Mendonça et al. [161] concluded that Candida spp., particularly C. albicans, were associated with $\mathrm{OM}$ in patients with hematological malignancies. However, Westbrook et al. [162] and Epstein et al. [163] did not report a positive correlation between Candida colonization and the presence or severity of OM in HSCT patients. These results indicate that the role of Candida species in the pathogenesis of OM remains to be elucidated in more detail.

Interestingly, van der Velden et al. [164] suggested that the mycobiome has a role in the pathogenesis of aGvHD. Candida spp. colonization of the mucosa may trigger intestinal aGvHD, potentially by the induction of Th17/IL-23 responses through activation of pattern recognition receptors by fungal motifs. Whether this also may occur in the oral cavity deserves further investigation.

Noncandidal fungal organisms may be also associated with oral infection in immunocompromised cancer patients, including infection by species of Aspergillus, mucormycosis, and Rhizopus [165]. Lesions associated with these fungi may resemble OM lesions but more detailed microbiologic documentation is needed.

4.3. Viral Infections. Viral infections of the oral cavity or the perioral region induce pain and discomfort. This may lead to reduced nutritional intake causing dehydration and malnutrition [166]. Moreover, viruses may give rise to systemic infectious complications and may trigger GvHD [167, 168].

Most often, herpes simplex virus (HSV), varicella-zoster virus (VZV), and Epstein-Barr virus (EBV) infections result from reactivation of latent virus, while cytomegalovirus (CMV) infections can result from either virus reactivation or via a newly acquired virus [169].

Most HSCT recipients receive prophylactic antiviral agents to prevent herpes viral reactivation. This reduces viral shedding and herpetic lesions, although reactivation is still possible in patients receiving prophylaxis [170].

When reactivation of HSV-1 occurs, ulcers may develop and aggravate OM, or they may be confused with this condition [171]. Rüping et al. [172] studied the association of IL- 1 and TNF- $\alpha$ in oral saliva and viral pathogens with the severity of ulcerations in autologous HSCT. An association of the severity of oral ulceration and HSV reactivation was demonstrated. Similarly van der Beek et al. [173] reported that oral shedding of HSV-1 predicts ulcerations. However, in these studies patients did not receive antiviral prophylaxis, whereas in HSCT recipients getting acyclovir prophylaxis HSV seems not a major etiologic agent of ulcerative OM [174].

VZV infection distributes via dermatomes. Like HSV1 and $-2, V Z V$ is latent in neurons, but viral particles are transported via axons to mucosa where the virus continues replicating in epithelial cells. Increased risk of VZV reactivation extends from three to twelve months after transplant, with allogeneic transplant recipients being at the highest risk [166].

CMV remains a major cause of morbidity, particularly in allogeneic HSCT recipients [175]. Salivary glands seem an important reservoir of CMV [176], as the virus can be shed in saliva and infected saliva is the main mechanism for transmitting CMV [177]. Correia-Silva et al. [176] found a positive correlation between CMV DNA loads in saliva and blood in allogeneic HSCT recipients. Although a recent study did not find a correlation between CMV in oral rinsing samples and oral ulcerations [173], oral ulceration due to CMV and cases of coinfection of HSV and CMV in oral ulcers have been reported [178]. CMV infection causes monocyte and T-cell activation and activation of the TNF system, concomitant with an increase in plasma levels of IL-10 [179]. Moreover, CMV may modulate immunological status of host cells by inducing local production of proinflammatory cytokines such as TNF, IL-1, IL-6, IL-8, and IL-10 [180, 181].

Liu et al. [182] investigated the mechanism of CMVspecific T-cell immune responses after HSCT in CMVspecific CD8+ T cells. They could not define the critical threshold or absolute number of CMV-specific CD8+ T cells that protect against CMV reactivation. Impaired reconstitution of Tregs may also be associated with CMV infection [183]. 
HSCT recipients may be at risk of developing EBV-related lymphomas and EBV-associated carcinomas of the head and neck region [184]. Posttransplantation lymphoproliferative disorder (PTLD) is the most common malignancy in the first year following allogeneic HSCT. The Waldeyer ring is more frequently involved [185]. Oral involvement of PTLD is rare; it may manifest as a crater-like gingival defect or an ulcerated dark-red mass [186]. In addition, oral hairy leukoplakia has been attributed to EBV infection in HSCT recipients.

Oral lesions caused by nonherpes viruses including adenovirus and human papilloma virus (HPV) have been described. Patients with increased cutaneous HPV lesions will often demonstrate oral lesions. A case of rapidly enlarging, biopsy-documented oral verruca vulgaris in a patient undergoing myeloablative HSCT has been reported [187].

\section{Taste Dysfunction}

Taste dysfunction (dysgeusia) negatively influences QoL and may lead to impaired nutrition and weight loss [188]. While conditioning regimen-related dysgeusia is typically associated with the onset of $\mathrm{OM}$ and resolves one to two months following HSCT [189], taste disorders may persist or develop de novo in allogeneic HSCT recipients [190]. Patients may report a rapid decrease in their sense of taste that is temporally associated with the onset or exacerbation of $\mathrm{cGvHD}$, suggesting that the epithelial-derived taste receptor cell is an immune-based target.

Antibiotics may have a negative impact on taste, whereas drugs used to prevent and treat GvHD (e.g., cyclosporine, mTOR inhibitors) can also induce neurological changes that result in altered taste [76].

\section{Late Complications}

With increased numbers of survivors, late effects of HSCT and concomitant therapies have become of increasing importance. Hyposalivation may persist when associated with salivary gland cGvHD, putting patients at risk for rapidly progressing dental demineralization and caries. Other complications include osteoporosis and bisphosphonate-related jaw necrosis. In addition, disturbances in tooth formation and jaw growth and development may be present in pediatric HSCT survivors [191].

Among these late effects, second malignancies have been recognized, including PTLD, hematologic malignancies, and solid tumors [192]. Solid tumors may develop many years after HSCT. In the vast majority of cases, oral tumors are squamous cell carcinomas (SCC). Several authors have described cases of SCC at oral and skin sites previously affected by cGvHD-related inflammatory processes, suggesting that $\mathrm{CGvHD}$ is a risk factor. In addition, prolonged immunosuppressive therapy may contribute to SCC risk. In a large retrospective study, HSCT recipients had a 20 - to 30 -fold risk for oral cancer 10 years or more after allogeneic HSCT [193]. Changes in the oral mucosa due to GvHD can make early detection and diagnosis of SCC clinically challenging. Longterm follow-up of HSCT patients is recommended to detect cancers at an early stage, and patients should be informed of cancer risk and educated to avoid life styles that can potentiate the risk of developing oral SCC.

\section{Discussion and Suggestions for Future Research}

Oral complications contribute significantly to morbidity and sometimes to mortality in HSCT recipients. A better understanding of the pathobiology of these complications and risk factors is necessary in order to develop more efficient preventative and therapeutic strategies.

HSCT conditioning regimens are important parameters determining OM risk, but patients differ considerably in their susceptibility to develop severe OM. Exciting progress has been made in predicting an individual's genetic risk for severe OM following conditioning for autologous HSCT by Sonis et al., who recently identified a SNP-based Bayesian network developed from saliva-sourced DNA [12]. Studies in larger number of HSCT recipients may ultimately result in a clinically useful saliva-based tool predicting severe OM. In addition, studies evaluating the role of the oral microbiome in maintaining oral homeostasis versus aggravating $\mathrm{OM}$ are promising [49].

Recently it has been suggested that cancer regimen related adverse events do not occur in isolation but rather develop in clusters [194]. Toxicities may be related with regard to the time of their development only, but there may be also causal relationships in which one toxicity predisposes to a subsequent complication. Moreover, toxicities of cancer treatment may have a common pathobiological background and share genetically determined and other risk factors [195]. As discussed above, inflammation, particularly the upregulation of proinflammatory cytokine pathways, is a major common driver of complications in HSCT recipients and interventions blocking these pathways may affect multiple complications.

Oral complications that seem to be interrelated include OM, hyposalivation, taste alterations, oral infections, and oral GvHD, although in the past most studies have focused on isolated toxicities, and more research is necessary to assess the nature of relationships. Oral complications also link to complications involving nonoral tissues as well as those manifesting systemically. For example, in neutropenic HSCT recipients OM is associated with bacteremia, fever, and sepsis [148]. Such associations may, at least in part, explain the observation that $\mathrm{OM}$ is associated with an increased risk to early nontumor related mortality in HSCT recipients $[6,64,65]$.

In addition to having a genetic predisposition for (multiple) inflammatory complications of HSCT, the presence of inflammation may lead to a dysregulated and exaggerated inflammatory response following a subsequent inflammatory stimulus. Interestingly, a recent study reported that, at the time of diagnosis of acute leukemia, high prechemotherapy plasma levels of both pro- and anti-inflammatory cytokines and low levels of an antimicrobial protein pro-LL-37 were associated with the highest OM risk, suggesting that a proinflammatory state preceding high-dose chemotherapy may predispose to complications [196]. 
Similarly, it has been proposed that periodontitis (present before the initiation of cancer treatment) may coinduce an exaggerated inflammatory response following (chemo)radiation in patients with head and neck cancer, leading to more severe OM [197]. It is well established that periodontal disease induces low-grade systemic inflammation characterized by increased levels of proinflammatory cytokines and acute phase proteins in peripheral blood (reviewed by van Dyke and Winkelhoff, 2013 [198]). This is the result of bacteria or bacterial and inflammatory products translocating through inflamed and ulcerated pocket epithelium into the circulation. Periodontitis and OM may be associated with a primed inflammatory response as proposed by the "two-hit" model. The model has previously been used to explain the pathogenesis of acute respiratory distress syndrome (ARDS) following cardiopulmonary bypass [199] and the association between periodontitis and inflammation driven systemic diseases including rheumatoid arthritis [200, 201].

Likewise, it can be hypothesized that oral infections including periodontitis may predispose to OM in HSCT recipients [2]. And taking this concept a step further, it may be speculated that inflammatory conditions (oral or elsewhere) either present before cytotoxic therapy, or developing as a result of therapy may predispose to other inflammationdriven acute or late complications in HSCT recipients. For example, there is anecdotal evidence that periodontal inflammation triggers oral GvHD, whereas GvHD ameliorates when periodontal or other foci of infection are eliminated. Likewise periodontitis and/or OM may be involved in sepsis risk even in the absence of bacteremia. Although a relationship between gastrointestinal mucositis, fever, and increased levels of inflammatory markers in the absence of bacteremia has been proposed [57, 202], the relative contribution of OM to systemic inflammation remains to be investigated.

To explore these hypotheses, longitudinal observational studies involving large numbers of patients looking into associations of oral and nonoral complications and their potentially common underlying mechanisms are needed. Such studies may point to the need of combined risk assessment. Furthermore, investigations using novel techniques will provide an opportunity to evaluate the role of the oral and gastrointestinal microbiome in mucositis and GvHD. Together with studies aimed at assessing the relationship between the microbiome and host factors including epithelial defense mechanisms, this may lead to successful strategies to prevent or ameliorate these complications [203].

Moreover, longitudinal studies using salivary samples may identify genetic risk factors for OM as well as for other regimen related complications [12]. In addition, studies may identify salivary biomarkers that may predict or facilitate diagnosis of $\mathrm{OM}$ and GvHD or their response to therapy.

In conclusion, a more holistic approach that includes clinical and translational studies on oral as well as nonoral complications of HSCT may lead to a better understanding of potential commonalities between complications and may open new avenues for prevention and treatment.

\section{Conflict of Interests}

The authors declare that there is no conflict of interests regarding the publication of this paper.

\section{References}

[1] M. Y. Shapira, P. Tsirigotis, I. B. Resnick, R. Or, A. Abdul-Hai, and S. Slavin, "Allogeneic hematopoietic stem cell transplantation in the elderly," Critical Reviews in Oncology/Hematology, vol. 64, no. 1, pp. 49-63, 2007.

[2] J. E. Raber-Durlacher, A. Barasch, D. E. Peterson, R. V. Lalla, M. M. Schubert, and W. E. Fibbe, "Oral complications and management considerations in patients treated with high-dose chemotherapy," Supportive Cancer Therapy, vol. 1, pp. 219-229, 2004.

[3] G. J. Barker, J. B. Epstein, K. B. Williams, M. Gorsky, and J. E. Raber-Durlacher, "Current practice and knowledge of oral care for cancer patients: a survey of supportive health care providers," Supportive Care in Cancer, vol. 13, no. 1, pp. 32-41, 2005.

[4] M. T. Brennan, L. S. Elting, and F. K. L. Spijkervet, "Systematic reviews of oral complications from cancer therapies, Oral Care Study Group, MASCC/ISOO: methodology and quality of the literature," Supportive Care in Cancer, vol. 18, no. 8, pp. 979-984, 2010.

[5] A. Barasch and J. B. Epstein, "Management of cancer therapyinduced oral mucositis," Dermatologic Therapy, vol. 24 , no. 4 , pp. 424-431, 2011.

[6] S. T. Sonis, G. Oster, H. Fuchs et al., "Oral mucositis and the clinical and economic outcomes of hematopoietic stem-cell transplantation," Journal of Clinical Oncology, vol. 19, no. 8, pp. 2201-2205, 2001.

[7] S. T. Sonis, L. S. Elting, D. Keefe et al., "Perspectives on cancer therapy-induced mucosal injury: pathogenesis, measurement, epidemiology, and consequences for patients," Cancer, vol. 100, no. 9, pp. 1995-2025, 2004.

[8] L. A. Bellm, J. B. Epstein, A. Rose-Ped, P. Martin, and H. J. Fuchs, "Patient reports of complications of bone marrow transplantation," Supportive Care in Cancer, vol. 8, no. 1, pp. 3339, 2000.

[9] A. M. Wardley, G. C. Jayson, R. Swindell et al., "Prospective evaluation of oral mucositis in patients receiving myeloablative conditioning regimens and haemopoietic progenitor rescue," British Journal of Haematology, vol. 110, no. 2, pp. 292-299, 2000.

[10] S. McCann, M. Schwenkglenks, P. Bacon et al., "The prospective oral mucositis audit: relationship of severe oral mucositis with clinical and medical resource use outcomes in patients receiving high-dose melphalan or BEAM-conditioning chemotherapy and autologous SCT," Bone Marrow Transplantation, vol. 43, no. 2, pp. 141-147, 2009.

[11] K. Robien, M. M. Schubert, B. Bruemmer, M. E. Lloid, J. D. Potter, and C. M. Ulrich, "Predictors of oral mucositis in patients receiving hematopoietic cell transplants for chronic myelogenous leukemia," Journal of Clinical Oncology, vol. 22, no. 7, pp. 1268-1275, 2004.

[12] S. Sonis, J. Antin, M. Tedaldi, and G. Alterovitz, "SNP-based Bayesian networks can predict oral mucositis risk in autologous stem cell transplant recipients," Oral Diseases, vol. 19, no. 7, pp. 721-727, 2013.

[13] L. Anthony, J. Bowen, A. Garden, I. Hewson, and S. Sonis, "New thoughts on the pathobiology of regimen-related mucosal 
injury," Supportive Care in Cancer, vol. 14, no. 6, pp. 516-518, 2006.

[14] K. Bogunia-Kubik, M. Polak, and A. Lange, "TNF polymorphisms are associated with toxic but not with aGVHD complications in the recipients of allogeneic sibling haematopoietic stem cell transplantation," Bone Marrow Transplantation, vol. 32, no. 6, pp. 617-622, 2003.

[15] K. Takahashi, Y. Soga, Y. Murayama et al., "Oral mucositis in patients receiving reduced-intensity regimens for allogeneic hematopoietic cell transplantation: comparison with conventional regimen," Supportive Care in Cancer, vol. 18, no. 1, pp. 115-119, 2010.

[16] O. Ringden, T. Erkers, J. Aschan et al., "A prospective randomized toxicity study to compare reduced-intensity and myeloablative conditioning in patients with myeloid leukaemia undergoing allogeneic haematopoietic stem cell transplantation," Journal of Internal Medicine, vol. 274, pp. 153-162, 2013.

[17] D. M. Keefe, M. M. Schubert, L. S. Elting et al., "Updated clinical practice guidelines for the prevention and treatment of mucositis," Cancer, vol. 109, no. 5, pp. 820-831, 2007.

[18] N. Al-Dasooqi, S. T. Sonis, J. M. Bowen et al., "Emerging evidence on the pathobiology of mucositis," Supportive Care in Cancer, vol. 21, pp. 2075-2083, 2013.

[19] S. T. Sonis, "The pathobiology of mucositis," Nature Reviews Cancer, vol. 4, no. 4, pp. 277-284, 2004.

[20] J. W. Denham and M. Hauer-Jensen, "The radiotherapeutic injury-a complex 'wound"' Radiotherapy and Oncology, vol. 63, no. 2, pp. 129-145, 2002.

[21] A. S. J. Yeoh, J. M. Bowen, R. J. Gibson, and D. M. K. Keefe, "Nuclear factor $\kappa \mathrm{B}(\mathrm{NF} \kappa \mathrm{B})$ and cyclooxygenase-2 (Cox2) expression in the irradiated colorectum is associated with subsequent histopathological changes," International Journal of Radiation Oncology Biology Physics, vol. 63, no. 5, pp. 1295-1303, 2005.

[22] S. T. Sonis, "The biologic role for nuclear factor-kappaB in disease and its potential involvement in mucosal injury associated with anti-neoplastic therapy," Critical Reviews in Oral Biology and Medicine, vol. 13, no. 5, pp. 380-389, 2002.

[23] S. T. Sonis, R. L. Peterson, L. J. Edwards et al., "Defining mechanisms of action of interleukin-11 on the progression of radiation-induced oral mucositis in hamsters," Oral Oncology, vol. 36, no. 4, pp. 373-381, 2000.

[24] J. A. Bianco, F. R. Appelbaum, J. Nemunaitis et al., "Phase I-II trial of pentoxifylline for the prevention of transplant-related toxicities following bone marrow transplantation," Blood, vol. 78, no. 5, pp. 1205-1211, 1991.

[25] C. Ferrà, S. de Sanjosé, C. F. Lastra et al., "Pentoxifylline, ciprofloxacin and prednisone failed to prevent transplantrelated toxicities in bone marrow transplant recipients and were associated with an increased incidence of infectious complications," Bone Marrow Transplantation, vol. 20, no. 12, pp. 10751080, 1997.

[26] V. Lima, G. A. C. Brito, F. Q. Cunha et al., "Effects of the tumour necrosis factor- $\alpha$ inhibitors pentoxifylline and thalidomide in short-term experimental oral mucositis in hamsters," European Journal of Oral Sciences, vol. 113, no. 3, pp. 210-217, 2005.

[27] A. P. Freitas, F. S. Bitencourt, G. A. Brito et al., "Protein fraction of Calotropis procera latex protects against 5-fluorouracilinduced oral mucositis associated with downregulation of pivotal pro-inflammatory mediators," Naunyn-Schmiedeberg's Archives of Pharmacology, vol. 385, pp. 981-990, 2012.
[28] R. M. Logan, A. M. Stringer, J. M. Bowen et al., "The role of pro-inflammatory cytokines in cancer treatment-induced alimentary tract mucositis: pathobiology, animal models and cytotoxic drugs," Cancer Treatment Reviews, vol. 33, no. 5, pp. 448-460, 2007.

[29] M. Curra, M. A. Martins, I. S. Lauxen et al., "Effect of topical chamomile on immunohistochemical levels of IL-1beta and TNF-alpha in 5-fluorouracil-induced oral mucositis in hamsters," Cancer Chemotherapy and Pharmacology, vol. 71, pp. 293-299, 2013.

[30] M. Nomura, M. Kamata, H. Kojima, K. Hayashi, and S. Sawada, "Irsogladine maleate reduces the incidence of fluorouracilbased chemotherapy-induced oral mucositis," Annals of Oncology, vol. 24, pp. 1062-1066, 2013.

[31] J. E. Raber-Durlacher, B. von I, R. M. Logan et al., "Systematic review of cytokines and growth factors for the management of oral mucositis in cancer patients," Supportive Care in Cancer, vol. 21, pp. 343-355, 2013.

[32] N. Al-Dasooqi, R. J. Gibson, J. M. Bowen, R. M. Logan, A. M. Stringer, and D. M. Keefe, "Matrix metalloproteinases are possible mediators for the development of alimentary tract mucositis in the dark agouti rat," Experimental Biology and Medicine, vol. 235, no. 10, pp. 1244-1256, 2010.

[33] A. R. Al-Azri, R. J. Gibson, D. M. Keefe, and R. M. Logan, "Matrix metalloproteinases: do they play a role in mucosal pathology of the oral cavity?" Oral Diseases, vol. 19, pp. 347-359, 2013.

[34] S. Bamba, A. Andoh, H. Yasui, Y. Araki, T. Bamba, and Y. Fujiyama, "Matrix metalloproteinase-3 secretion from human colonic subepithelial myofibroblasts: role of interleukin-17," Journal of Gastroenterology, vol. 38, no. 6, pp. 548-554, 2003.

[35] I. Shoval, J. A. Kushner, B. Sukhu et al., "The relationship between mouthrinse matrix metalloproteinases (MMP-1, 8, 13) and albumin levels with the degree of oral mucositis in allogeneic stem cell transplant patients," Bone Marrow Transplantation, vol. 36, no. 1, pp. 33-38, 2005.

[36] A. Yeoh, R. Gibson, E. Yeoh et al., "Radiation therapy-induced mucositis: relationships between fractionated radiation, NF- $\kappa \mathrm{B}$, COX-1, and COX-2," Cancer Treatment Reviews, vol. 32, no. 8, pp. 645-651, 2006.

[37] N. Blijlevens and S. Sonis, "Palifermin (recombinant keratinocyte growth factor-1): a pleiotropic growth factor with multiple biological activities in preventing chemotherapy- and radiotherapy-induced mucositis," Annals of Oncology, vol. 18, no. 5, pp. 817-826, 2007.

[38] B. A. E. de Koning, J. M. van Dieren, D. J. Lindenbergh-Kortleve et al., "Contributions of mucosal immune cells to methotrexateinduced mucositis," International Immunology, vol. 18, no. 6, pp. 941-949, 2006.

[39] W. L. Trepicchio, M. Bozza, G. Pedneault, and A. J. Dorner, "Recombinant human IL-11 attenuates the inflammatory response through down-regulation of proinflammatory cytokine release and nitric oxide production," The Journal of Immunology, vol. 157, no. 8, pp. 3627-3634, 1996.

[40] J. H. Antin, S. J. Lee, D. Neuberg et al., "A phase I/II double-blind, placebo-controlled study of recombinant human interleukin-11 for mucositis and acute GVHD prevention in allogeneic stem cell transplantation," Bone Marrow Transplantation, vol. 29, no. 5, pp. 373-377, 2002.

[41] S. T. Sonis, A. G. van Vugt, J. P. O. Brien et al., “Transforming growth factor- $\beta 3$ mediated modulation of cell cycling and 
attenuation of 5-fluorouracil induced oral mucositis," European Journal of Cancer B: Oral Oncology, vol. 33, no. 1, pp. 47-54, 1997.

[42] C. L. Farrell, K. L. Rex, J. N. Chen et al., "The effects of keratinocyte growth factor in preclinical models of mucositis," Cell Proliferation, vol. 35, supplement 1, pp. 78-85, 2002.

[43] R. Spielberger, P. Stiff, W. Bensinger et al., "Palifermin for oral mucositis after intensive therapy for hematologic cancers," The New England Journal of Medicine, vol. 351, no. 25, pp. 25902598, 2004.

[44] C. L. Maynard, C. O. Elson, R. D. Hatton, and C. T. Weaver, "Reciprocal interactions of the intestinal microbiota and immune system," Nature, vol. 489, pp. 231-241, 2012.

[45] E. M. Brown, M. Sadarangani, and B. B. Finlay, "The role of the immune system in governing host-microbe interactions in the intestine," Nature Immunology, vol. 14, pp. 660-667, 2013.

[46] S. Dreizen, G. P. Bodey, and L. R. Brown, "Opportunistic gram negative bacillary infections in leukemia. Oral manifestations during myelosuppression," Postgraduate Medicine, vol. 55, no. 4, pp. 133-139, 1974.

[47] M. V. Martin and H. K. van Saene, "The role of oral microorganisms in cancer therapy," Current Opinion in Dentistry, vol. 2, pp. 81-84, 1992.

[48] J. J. Napeñas, M. T. Brennan, S. Coleman et al., "Molecular methodology to assess the impact of cancer chemotherapy on the oral bacterial flora: a pilot study," Oral Surgery, Oral Medicine, Oral Pathology, Oral Radiology and Endodontology, vol. 109, no. 4, pp. 554-560, 2010.

[49] Y. Ye, G. Carlsson, M. B. Agholme et al., "Oral bacterial community dynamics in paediatric patients with malignancies in relation to chemotherapy-related oral mucositis: a prospective study," Clinical Microbiology and Infection, vol. 19, no. 12, pp. 559-567, 2013.

[50] Y. Soga, Y. Maeda, F. Ishimaru et al., "Bacterial substitution of coagulase-negative staphylococci for streptococci on the oral mucosa after hematopoietic cell transplantation," Supportive Care in Cancer, vol. 19, no. 7, pp. 995-1000, 2011.

[51] A. M. G. A. Laheij, J. J. de Soet, P. A. von dem Borne et al., "Oral bacteria and yeasts in relationship to oral ulcerations in hematopoietic stem cell transplant recipients," Supportive Care in Cancer, vol. 20, pp. 3231-3240, 2012.

[52] T. K. Fábián, P. Hermann, A. Beck, P. Fejérdy, and G. Fábián, "Salivary defense proteins: their network and role in innate and acquired oral immunity," International Journal of Molecular Sciences, vol. 13, no. 4, pp. 4295-4320, 2012.

[53] A. Barasch and D. E. Peterson, "Risk factors for ulcerative oral mucositis in cancer patients: unanswered questions," Oral Oncology, vol. 39, no. 2, pp. 91-100, 2003.

[54] S. T. Sonis, "Oral mucositis in head and neck cancer," American Society of Clinical Oncology Educational Book, vol. 2013, pp. 236-240, 2013.

[55] S. T. Sonis, "New thoughts on the initiation of mucositis," Oral Diseases, vol. 16, no. 7, pp. 597-600, 2010.

[56] M. Panghal, V. Kaushal, S. Kadayan, and J. P. Yadav, "Incidence and risk factors for infection in oral cancer patients undergoing different treatments protocols," BMC Oral Health, vol. 12, article 22, 2012.

[57] W. J. F. M. van der Velden, N. M. A. Blijlevens, T. Feuth, and J. P. Donnelly, "Febrile mucositis in haematopoietic SCT recipients," Bone Marrow Transplantation, vol. 43, no. 1, pp. 55-60, 2009.

[58] M. S. Greenberg, S. G. Cohen, J. C. McKitrick, and P. A. Cassileth, "The oral flora as a source of septicemia in patients with acute leukemia," Oral Surgery Oral Medicine and Oral Pathology, vol. 53, no. 1, pp. 32-36, 1982.

[59] F. Baquero, J. Fernandez, F. Dronda et al., "Capnophilic and anaerobic bacteremia in neutropenic patients: an oral source," Reviews of Infectious Diseases, vol. 12, supplement 2, pp. S157S160, 1990.

[60] P. O. Laine, J. C. Lindqvist, S. O. Pyrhonen, I. M. StrandPettinen, L. M. Teerenhovi, and J. H. Meurman, "Oral infection as a reason for febrile episodes in lymphoma patients receiving cytostatic drugs," European Journal of Cancer B: Oral Oncology, vol. 28, no. 2, pp. 103-107, 1992.

[61] L. S. Elting, G. P. Bodey, and B. H. Keefe, "Septicemia and shock syndrome due to viridans streptococci: a case-control study of predisposing factors," Clinical Infectious Diseases, vol. 14, no. 6, pp. 1201-1207, 1992.

[62] A. Marron, J. Carratalà, E. González-Barca, A. FernándezSevilla, F. Alcaide, and F. Gudiol, "Serious complications of bacteremia caused by viridans streptococci in neutropenic patients with cancer," Clinical Infectious Diseases, vol. 31, no. 5, pp. 1126-1130, 2000.

[63] S. F. Costa, M. H. Miceli, and E. J. Anaissie, "Mucosa or skin as source of coagulase-negative staphylococcal bacteraemia?" The Lancet Infectious Diseases, vol. 4, pp. 278-286, 2004.

[64] A. P. Rapoport, L. F. M. Watelet, T. Linder et al., "Analysis of factors that correlate with mucositis in recipients of autologous and allogeneic stem-cell transplants," Journal of Clinical Oncology, vol. 17, no. 8, pp. 2446-2453, 1999.

[65] S. R. Fanning, L. Rybicki, M. Kalaycio et al., "Severe mucositis is associated with reduced survival after autologous stem cell transplantation for lymphoid malignancies," British Journal of Haematology, vol. 135, no. 3, pp. 374-381, 2006.

[66] J. L. Ferrara, J. E. Levine, P. Reddy, and E. Holler, "Graft-versushost disease," The Lancet, vol. 373, no. 9674, pp. 1550-1561, 2009.

[67] S. Vokurka, K. Steinerova, M. Karas, and V. Koza, "Characteristics and risk factors of oral mucositis after allogeneic stem cell transplantation with FLU/MEL conditioning regimen in context with BU/CY2," Bone Marrow Transplantation, vol. 44, no. 9, pp. 601-605, 2009.

[68] S. Vokurka, T. Svoboda, A. Jungova, M. Karas, and V. Koza, "Oral cryotherapy can significantly reduce oral mucositis but not acute GVHD incidence in Flu/Mel conditioning allo-SCT," Bone Marrow Transplantation, vol. 47, pp. 739-741, 2012.

[69] R. E. Billingham, "The biology of graft-versus-host reactions," Harvey Lectures, vol. 62, pp. 21-78, 1966.

[70] G. B. Vogelsang, L. Lee, and D. M. Bensen-Kennedy, "Pathogenesis and treatment of graft-versus-host disease after bone marrow transplant," Annual Review of Medicine, vol. 54, pp. 2952, 2003.

[71] J. B. Epstein, J. E. Raber-Drulacher, A. Wilkins, M. Chavarria, and H. Myint, "Advances in hematologic stem cell transplant: an update for oral health care providers," Oral Surgery, Oral Medicine, Oral Pathology, Oral Radiology and Endodontology, vol. 107, no. 3, pp. 301-312, 2009.

[72] A. Bacigalupo, "Management of acute graft-versus-host disease," British Journal of Haematology, vol. 137, no. 2, pp. 87-98, 2007.

[73] T. Ruutu, A. Gratwohl, T. de Witte et al., "Prophylaxis and treatment of GVHD: EBMT-ELN working group recommendations for a standardized practice," Bone Marrow Transplantation, vol. 49, no. 2, pp. 168-173, 2013. 
[74] M. M. Imanguli, I. Alevizos, R. Brown, S. Z. Pavletic, and J. C. Atkinson, "Oral graft-versus-host disease," Oral Diseases, vol. 14, no. 5, pp. 396-412, 2008.

[75] A. H. Filipovich, D. Weisdorf, S. Pavletic et al., "National Institutes of Health Consensus Development Project on criteria for clinical trials in chronic graft-versus-host disease. I.: diagnosis and staging working group report," Biology of Blood and Marrow Transplantation, vol. 11, no. 12, pp. 945-956, 2005.

[76] M. M. Schubert and M. E. P. Correa, "Oral Graft-Versus-Host disease," Dental Clinics of North America, vol. 52, no. 1, pp. 79109, 2008.

[77] S. Woo, S. J. Lee, and M. M. Schubert, "Graft-vs.-host disease," Critical Reviews in Oral Biology and Medicine, vol. 8, no. 2, pp. 201-216, 1997.

[78] S. Elad, M. Y. Shapira, S. McNeal et al., "Oral effects of nonmyeloablative stem cell transplantation: a prospective observational study," Quintessence International, vol. 39, no. 8, pp. 673678, 2008.

[79] S. Vokurka, T. Svoboda, M. Karas et al., "Significant oral graftversus-host disease after allogeneic stem cell transplantation with the FLU/MEL conditioning regimen," Medical Science Monitor, vol. 17, no. 9, pp. CR480-CR484, 2011.

[80] S. J. Lee and M. E. D. Flowers, "Recognizing and managing chronic graft-versus-host disease," Hematology/the Education Program of the American Society of Hematology. American Society of Hematology. Education Program, pp. 134-141, 2008.

[81] N. Treister, C. Duncan, C. Cutler, and L. Lehmann, "How we treat oral chronic graft-versus-host disease," Blood, vol. 120, pp. 3407-3418, 2012.

[82] K. M. Hull, I. Kerridge, and M. Schifter, "Long-term oral complications of allogeneic haematopoietic SCT", Bone Marrow Transplantation, vol. 47, no. 2, pp. 265-270, 2012.

[83] T. Daikeler, M. Mauramo, A. Rovo et al., "Sicca symptoms and their impact on quality of life among very long-term survivors after hematopoietic SCT," Bone Marrow Transplantation, vol. 48, pp. 988-993, 2013.

[84] N. S. Treister, S. Woo, E. W. O'Holleran, L. E. Lehmann, S. K. Parsons, and E. C. Guinan, "Oral chronic graft-versushost disease in pediatric patients after hematopoietic stem cell transplantation," Biology of Blood and Marrow Transplantation, vol. 11, no. 9, pp. 721-731, 2005.

[85] N. S. Treister, E. F. Cook Jr., J. Antin, S. J. Lee, R. Soiffer, and S. Woo, "Clinical evaluation of oral chronic Graft-Versus-Host disease," Biology of Blood and Marrow Transplantation, vol. 14, no. 1, pp. 110-115, 2008.

[86] M. M. Imanguli, J. C. Atkinson, S. A. Mitchell et al., "Salivary gland involvement in chronic graft-versus-host disease: prevalence, clinical significance, and recommendations for evaluation," Biology of Blood and Marrow Transplantation, vol. 16, no. 10, pp. 1362-1369, 2010.

[87] A. Vissink, F. R. Burlage, F. K. Spijkervet, E. C. Veerman, and A. V. Nieuw Amerongen, "Prevention and treatment of salivary gland hypofunction related to head and neck radiation therapy and chemotherapy," Supportive Cancer Therapy, vol. 1, pp. 111118, 2004.

[88] M. M. Imanguli, J. C. Atkinson, K. E. Harvey et al., "Changes in salivary proteome following allogeneic hematopoietic stem cell transplantation," Experimental Hematology, vol. 35, no. 2, pp. 184-192, 2007.

[89] M. Laaksonen, A. M. Ramseier, A. Rovó et al., "Longitudinal assessment of hematopoietic stem cell transplantation and hyposalivation," Journal of Dental Research, vol. 90, no. 10, pp. 1177-1182, 2011.

[90] P. Castellarin, K. Stevenson, M. Biasotto, A. Yuan, S. B. Woo, and N. S. Treister, "Extensive dental caries in patients with oral chronic graft-versus-host disease," Biology of Blood and Marrow Transplantation, vol. 18, pp. 1573-1579, 2012.

[91] M. J. García-F-Villalta, M. Pascual-López, M. Elices, E. Daudén, A. García-Diez, and J. Fraga, "Superficial mucoceles and lichenoid graft versus host disease: report of three cases," Acta Dermato-Venereologica, vol. 82, no. 6, pp. 453-455, 2002.

[92] J. L. M. Ferrara and P. Reddy, "Pathophysiology of graft-versushost disease," Seminars in Hematology, vol. 43, no. 1, pp. 3-10, 2006.

[93] A. C. Harris, J. L. Ferrara, and J. E. Levine, "Advances in predicting acute GVHD," British Journal of Haematology, vol. 160, pp. 288-302, 2013.

[94] D. W. van Bekkum, J. Roodenburg, P. J. Heidt, and D. van der Waaij, "Mitigation of secondary disease of allogeneic mouse radiation chimeras by modification of the intestinal microflora," Journal of the National Cancer Institute, vol. 52, no. 2, pp. 401404, 1974.

[95] G. R. Hill and J. L. M. Ferrara, "The primacy of the gastrointestinal tract as a target organ of acute graft-versus-host disease: rationale for the use of cytokine shields in allogeneic bone marrow transplantation," Blood, vol. 95, no. 9, pp. 2754-2759, 2000.

[96] R. Korngold, J. C. Marini, M. E. de Baca, G. F. Murphy, and J. Giles-Komar, "Role of tumor necrosis factor- $\alpha$ in graft-versushost disease and graft-versus-leukemia responses," Biology of Blood and Marrow Transplantation, vol. 9, no. 5, pp. 292-303, 2003.

[97] K. R. Cooke, G. R. Hill, J. M. Crawford et al., "Tumor necrosis factor- $\alpha$ production to lipopolysaccharide stimulation by donor cells predicts the severity of experimental acute graft-versushost disease," The Journal of Clinical Investigation, vol. 102, no. 10, pp. 1882-1891, 1998.

[98] T. Toubai, J. Tanaka, S. Paczesny, Y. Shono, P. Reddy, and M. Imamura, "Role of cytokines in the pathophysiology of acute graft-versus-host disease (GVHD)- are serum/plasma cytokines potential biomarkers for diagnosis of acute GVHD following allogeneic hematopoietic cell transplantation (AlloHCT)?" Current Stem Cell Research and Therapy, vol. 7, no. 3, pp. 229-239, 2012.

[99] R. R. Jenq, C. Ubeda, Y. Taur et al., "Regulation of intestinal inflammation by microbiota following allogeneic bone marrow transplantation," The Journal of Experimental Medicine, vol. 209, pp. 903-911, 2012.

[100] R. Korngold and J. Sprent, "Surface markers of T cells causing lethal graft-vs-host disease to class I vs class II H-2 differences," The Journal of Immunology, vol. 135, no. 5, pp. 3004-3010, 1985.

[101] W. Krenger, G. R. Hill, and J. L. M. Ferrara, "Cytokine cascades in acute graft-versus-host disease," Transplantation, vol. 64, no. 4, pp. 553-558, 1997.

[102] J. H. Antin and J. L. M. Ferrara, "Cytokine dysregulation and acute graft-versus-host disease," Blood, vol. 80, no. 12, pp. 29642968, 1992.

[103] P. Reddy and J. L. M. Ferrara, "Immunobiology of acute graftversus-host disease," Blood Reviews, vol. 17, no. 4, pp. 187-194, 2003.

[104] R. G. Resende, M. H. Guimaraes Abreu, L. N. Souza, M. E. Silva, R. S. Gomez, and J. F. Correia-Silva, "Association between 
IL1B (+3954) polymorphisms and IL-1 $\beta$ levels in blood and saliva, together with acute graft-versus-host disease," Journal of Interferon and Cytokine Research, vol. 33, pp. 392-397, 2013.

[105] G. R. Hill, T. Teshima, V. I. Rebel et al., "The p55 TNF- $\alpha$ receptor plays a critical role in T cell alloreactivity," The Journal of Immunology, vol. 164, no. 2, pp. 656-663, 2000.

[106] P.-F. Piguet, G. E. Grau, B. Allet, and P. Vassalli, “Tumor necrosis factor/cachectin is an effector of skin and gut lesions of the acute phase of graft-vs-host disease," Journal of Experimental Medicine, vol. 166, no. 5, pp. 1280-1289, 1987.

[107] G. R. Brown, E. Lee, and D. L. Thiele, “TNF-TNFR2 interactions are critical for the development of intestinal graft-versus-host disease in MHC class II-disparate $(\mathrm{C} 57 \mathrm{BL} / 6 \mathrm{~J} \rightarrow \mathrm{C} 57 \mathrm{BL} / 6 \mathrm{~J} \times$ bm12)F1 mice," The Journal of Immunology, vol. 168, no. 6, pp. 3065-3071, 2002.

[108] J. M. Fall-Dickson, S. A. Mitchell, S. Marden et al., "Oral symptom intensity, health-related quality of life, and correlative salivary cytokines in adult survivors of hematopoietic stem cell transplantation with oral chronic graft-versus-host disease," Biology of Blood and Marrow Transplantation, vol. 16, no. 7, pp. 948-956, 2010.

[109] H. Gao, A. Sun, Y. Han et al., "Clinical significance of TNFalpha, IL-1beta and IFN-gamma levels at early phase after allogeneic hematopoietic stem cell transplantation," Zhongguo Shi Yan Xue Ye Xue Za Zhi, vol. 17, no. 5, pp. 1321-1325, 2009.

[110] C. Pasare and R. Medzhitov, "Toll pathway-dependent blockade of CD4+CD25+ T cell-mediated suppression by dendritic cells," Science, vol. 299, no. 5609, pp. 1033-1036, 2003.

[111] D. Noguchi, D. Wakita, T. Ohkuri et al., "Blockade of IL-6signaling inhibits the pathogenesis of CD4+ T cell-mediated lethal graft-versus-host reaction against minor histocompatibility antigen," Immunology Letters, vol. 136, no. 2, pp. 146-155, 2011.

[112] W. Krenger, G. Falzarano, J. Delmonte Jr., K. M. Snyder, J. C. H. Byon, and J. L. M. Ferrara, "Interferon- $\gamma$ suppresses T-cell proliferation to mitogen via the nitric oxide pathway during experimental acute graft-versus-host disease," Blood, vol. 88, no. 3, pp. 1113-1121, 1996.

[113] X. Zhao, L. Xu, S. Lu, and X. Huang, "IL-17-producing T cells contribute to acute graft-versus-host disease in patients undergoing unmanipulated blood and marrow transplantation," European Journal of Immunology, vol. 41, no. 2, pp. 514526, 2011.

[114] M. Normanton and L. C. Marti, "Current data on IL-17 and Th17 cells and implications for graft versus host disease," Einstein, vol. 11, pp. 237-246, 2013.

[115] Z. Yao, S. L. Painter, W. C. Fanslow et al., "Human IL-17: a novel cytokine derived from T cells," The Journal of Immunology, vol. 155, no. 12, pp. 5483-5486, 1995.

[116] N. Fujii, A. Hiraki, K. Aoe et al., "Serum cytokine concentrations and acute graft-versus-host disease after allogeneic peripheral blood stem cell transplantation: concurrent measurement of ten cytokines and their respective ratios using cytometric bead array," International Journal of Molecular Medicine, vol. 17, no. 5, pp. 881-885, 2006.

[117] K. W. Moore, A. O'Garra, R. de Waal Malefyt, P. Vieira, and T. R. Mosmann, "Interleukin-10," Annual Review of Immunology, vol. 11, pp. 165-190, 1993.

[118] I. Tawara, Y. Sun, C. Liu et al., "Donor- but not host-derived interleukin-10 contributes to the regulation of experimental graft-versus-host disease," Journal of Leukocyte Biology, vol. 91, pp. 667-675, 2012.
[119] J. Cavet, P. G. Middleton, M. Segall, H. Noreen, S. M. Davies, and A. M. Dickinson, "Recipient tumor necrosis factor- $\alpha$ and interleukin-10 gene polymorphisms associate with early mortality and acute graft-versus-host disease severity in HLAmatched sibling bone marrow transplants," Blood, vol. 94, no. 11, pp. 3941-3946, 1999.

[120] E. Holler, M. G. Roncarolo, R. Hintermeier-Knabe et al., "Prognostic significance of increased IL-10 production in patients prior to allogeneic bone marrow transplantation," Bone Marrow Transplantation, vol. 25, no. 3, pp. 237-241, 2000.

[121] C. Bucher, L. Koch, C. Vogtenhuber et al., "IL-21 blockade reduces graft-versus-host disease mortality by supporting inducible T regulatory cell generation," Blood, vol. 114, no. 26, pp. 5375-5384, 2009.

[122] M. Couturier, B. Lamarthee, J. Arbez et al., "IL-22 deficiency in donor $\mathrm{T}$ cells attenuates murine acute graft-versus-host disease mortality while sparing the graft-versus-leukemia effect," Leukemia, vol. 27, pp. 1527-1537, 2013.

[123] A. M. Hanash, J. A. Dudakov, G. Hua et al., "Interleukin-22 protects intestinal stem cells from immune-mediated tissue damage and regulates sensitivity to graft versus host disease," Immunity, vol. 37, pp. 339-350, 2012.

[124] R. M. Dean, T. Fry, C. Mackall et al., "Association of serum interleukin-7 levels with the development of acute graft-versushost disease," Journal of Clinical Oncology, vol. 26, no. 35, pp. 5735-5741, 2008.

[125] E. Bolotin, G. Annett, R. Parkman, and K. Weinberg, "Serum levels of IL-7 in bone marrow transplant recipients: relationship to clinical characteristics and lymphocyte count," Bone Marrow Transplantation, vol. 23, no. 8, pp. 783-788, 1999.

[126] J. M. Coghill, S. Sarantopoulos, T. P. Moran, W. J. Murphy, B. R. Blazar, and J. S. Serody, "Effector CD4+ T cells, the cytokines they generate, and GVHD: something old and something new," Blood, vol. 117, no. 12, pp. 3268-3276, 2011.

[127] L. E. Harrington, R. D. Hatton, P. R. Mangan et al., "Interleukin 17-producing CD4+ effector T cells develop via a lineage distinct from the T helper type 1 and 2 lineages," Nature Immunology, vol. 6, no. 11, pp. 1123-1132, 2005.

[128] J. S. Kim, S. Kim, J. Cheong et al., "Clinical significance of B cellactivating factor (BAFF) and a proliferation-inducing ligand (APRIL) in acute graft-versus-host disease after allogeneic hematopoietic stem cell transplantation," Korean Journal of Hematology, vol. 46, no. 3, pp. 175-179, 2011.

[129] Y. Kataoka, T. Iwasaki, T. Kuroiwa et al., “The role of donor T cells for target organ injuries in acute and chronic graft-versushost disease," Immunology, vol. 103, no. 3, pp. 310-318, 2001.

[130] J. A. Pérez-Simón, I. Sánchez-Abarca, M. Díez-Campelo, D. Caballero, and J. San Miguel, "Chronic graft-versus-host disease: pathogenesis and clinical management," Drugs, vol. 66, no. 8, pp. 1041-1057, 2006.

[131] S. C. Morris, R. L. Cheek, P. L. Cohen, and R. A. Eisenberg, "Allotype-specific immunoregulation of autoantibody production by host B cells in chronic graft-versus-host disease," The Journal of Immunology, vol. 144, no. 3, pp. 916-922, 1990.

[132] D. B. Miklos, H. T. Kim, K. H. Miller et al., "Antibody responses to $\mathrm{H}-\mathrm{Y}$ minor histocompatibility antigens correlate with chronic graft-versus-host disease and disease remission," Blood, vol. 105, no. 7, pp. 2973-2978, 2005.

[133] S. Sarantopoulos, K. E. Stevenson, H. T. Kim et al., "High levels of B-cell activating factor in patients with active chronic graftversus-host disease," Clinical Cancer Research, vol. 13, no. 20, pp. 6107-6114, 2007. 
[134] J. S. Young, T. Wu, Y. Chen et al., "Donor B cells in transplants augment clonal expansion and survival of pathogenic CD4+ T cells that mediate autoimmune-like chronic graft-versus-host disease," The Journal of Immunology, vol. 189, pp. 222-233, 2012.

[135] A. J. Beres and W. R. Drobyski, "The role of regulatory T cells in the biology of graft versus host disease," Frontiers of Immunology, vol. 4, p. 163, 2013.

[136] H. Nishimori, Y. Maeda, and M. Tanimoto, "Chronic graftversus-host disease: disease biology and novel therapeutic strategies," Acta Medica Okayama, vol. 67, pp. 1-8, 2013.

[137] D. de Wit, M. van Mechelen, C. Zanin et al., "Preferential activation of Th2 cells in chronic graft-versus-host reaction," The Journal of Immunology, vol. 150, no. 2, pp. 361-366, 1993.

[138] V. Rus, A. Svetic, P. Nguyen, W. C. Gause, and C. S. Via, "Kinetics of Th1 and Th2 cytokine production during the early course of acute and chronic murine graft-versus-host disease: regulatory role of donor CD8+ T cells," The Journal of Immunology, vol. 155, no. 5, pp. 2396-2406, 1995.

[139] F. M. Sanchez-Guijo, L. Sanchez-Abarca, C. Bueno et al., "Longterm immune recovery of patients undergoing allogeneic stem cell transplantation: a comparison with their respective sibling donors," Biology of Blood and Marrow Transplantation, vol. 11, no. 5, pp. 354-361, 2005.

[140] D. Körholz, D. Kunst, L. Hempel et al., "Decreased interleukin 10 and increased interferon- $\gamma$ production in patients with chronic graft-versus-host disease after allogeneic bone marrow transplantation," Bone Marrow Transplantation, vol. 19, no. 7, pp. 691-695, 1997.

[141] H. Nishimori, Y. Maeda, T. Teshima et al., "Synthetic retinoid Am80 ameliorates chronic graft-versus-host disease by downregulating Th1 and Th17," Blood, vol. 119, no. 1, pp. 285-295, 2012.

[142] M. M. Imanguli, W. D. Swaim, S. C. League, R. E. Gress, S. Z. Pavletic, and F. T. Hakim, "Increased T-bet+ cytotoxic effectors and type i interferon-mediated processes in chronic graft-versus-host disease of the oral mucosa," Blood, vol. 113, no. 15, pp. 3620-3630, 2009.

[143] T. C. Soares, M. E. Correa, G. F. Cintra, E. C. Miranda, and M. L. Cintra, "The impact of morphological and immunohistological changes in minor salivary glands on the health of the oral cavity in HSCT patients," Bone Marrow Transplantation, vol. 48, no. 12, pp. 1525-1529, 2013.

[144] R. M. Nagler, D. Laufer, and A. Nagler, "Parotid gland dysfunction in an animal model of chronic graft-vs-host disease," Archives of Otolaryngology-Head and Neck Surgery, vol. 122, no. 10, pp. 1057-1060, 1996.

[145] J. B. Epstein and A. W. Chow, "Oral complications associated with immunosuppression and cancer therapies," Infectious Disease Clinics of North America, vol. 13, no. 4, pp. 901-923, 1999.

[146] S. Gorr, "Antimicrobial peptides in periodontal innate defense," Frontiers of Oral Biology, vol. 15, pp. 84-98, 2012.

[147] S. Vokurka, J. Skardova, R. Hruskova et al., "The effect of polyvinylpyrrolidone-sodium hyaluronate gel (Gelclair) on oral microbial colonization and pain control compared with other rinsing solutions in patients with oral mucositis after allogeneic stem cells transplantation," Medical Science Monitor, vol. 17, no. 10, pp. CR572-CR576, 2011.

[148] T. J. Ruescher, A. Sodeifi, S. J. Scrivani, L. B. Kaban, and S. T. Sonis, "The impact of mucositis on alpha-hemolytic streptococcal infection in patients undergoing autologous bone marrow transplantation for hematologic malignancies," Cancer, vol. 82, pp. 2275-2281, 1998.
[149] C. J. Graber, K. N. F. de Almeida, J. C. Atkinson et al., "Dental health and viridans streptococcal bacteremia in allogeneic hematopoietic stem cell transplant recipients," Bone Marrow Transplantation, vol. 27, no. 5, pp. 537-542, 2001.

[150] J. E. Raber-Durlacher, J. B. Epstein, J. Raber et al., "Periodontal infection in cancer patients treated with high-dose chemotherapy," Supportive Care in Cancer, vol. 10, no. 6, pp. 466-473, 2002.

[151] J. E. Raber-Durlacher, A. M. Laheij, J. B. Epstein et al., "Periodontal status and bacteremia with oral viridans streptococci and coagulase negative staphylococci in allogeneic hematopoietic stem cell transplantation recipients: a prospective observational study," Supportive Care in Cancer, vol. 21, no. 6, pp. 16211627, 2013.

[152] B. Alt-Epping, R. K. Nejad, K. Jung, U. Groß, and F. Nauck, "Symptoms of the oral cavity and their association with local microbiological and clinical findings-a prospective survey in palliative care," Supportive Care in Cancer, vol. 20, no. 3, pp. 531537, 2012.

[153] G. Dahlén, S. Blomquist, and A. Carlén, "A retrospective study on the microbiology in patients with oral complaints and oral mucosal lesions," Oral Diseases, vol. 15, no. 4, pp. 265-272, 2009.

[154] 2013, http://www.cancer.gov/cancertopics/pdq/supportivecare/ oralcomplications.

[155] R. Trenschel, R. Peceny, V. Runde et al., "Fungal colonization and invasive fungal infections following allogeneic BMT using metronidazole, ciprofloxacin and fluconazole or ciprofloxacin and fluconzole as intestinal decontamination," Bone Marrow Transplantation, vol. 26, no. 9, pp. 993-997, 2000.

[156] R. V. Lalla, M. C. Latortue, C. H. Hong et al., "A systematic review of oral fungal infections in patients receiving cancer therapy," Supportive Care in Cancer, vol. 18, no. 8, pp. 985-992, 2010.

[157] R. A. Whiley, A. T. Cruchley, C. Gore, and E. HagiPavli, "Candida albicans strain-dependent modulation of proinflammatory cytokine release by in vitro oral and vaginal mucosal models," Cytokine, vol. 57, no. 1, pp. 89-97, 2012.

[158] A. Dongari-Bagtzoglou and P. L. Fidel Jr., "The host cytokine responses and protective immunity in oropharyngeal candidiasis," Journal of Dental Research, vol. 84, no. 11, pp. 966-977, 2005.

[159] C. C. Villar, H. Kashleva, A. P. Mitchell, and A. DongariBagtzoglou, "Invasive phenotype of Candida albicans affects the host proinflammatory response to infection," Infection and Immunity, vol. 73, no. 8, pp. 4588-4595, 2005.

[160] Y.-K. Chen, H.-A. Hou, J.-M. Chow, Y.-C. Chen, P.-R. Hsueh, and H.-F. Tien, "The impact of oral herpes simplex virus infection and candidiasis on chemotherapy-induced oral mucositis among patients with hematological malignancies," European Journal of Clinical Microbiology and Infectious Diseases, vol. 30, no. 6, pp. 753-759, 2011.

[161] R. M. H. de Mendonça, M. de Araújo, C. E. Levy et al., "Prospective evaluation of HSV, Candida spp., and oral bacteria on the severity of oral mucositis in pediatric acute lymphoblastic leukemia," Supportive Care in Cancer, vol. 20, pp. 1101-1107, 2012.

[162] S. D. Westbrook, W. R. Kirkpatrick, N. P. Wiederhold et al., "Microbiology and epidemiology of oral yeast colonization in hemopoietic progenitor cell transplant recipients," Oral Surgery, Oral Medicine, Oral Pathology, Oral Radiology, and Endodontics, vol. 115, pp. 354-358, 2013.

[163] J. B. Epstein, P. J. Hancock, and S. Nantel, "Oral candidiasis in hematopoietic cell transplantation patients: an outcome-based analysis," Oral Surgery, Oral Medicine, Oral Pathology, Oral Radiology, and Endodontics, vol. 96, no. 2, pp. 154-163, 2003. 
[164] W. J. van der Velden, M. G. Netea, A. F. de Haan, G. A. Huls, J. P. Donnelly, and N. M. Blijlevens, "Role of the mycobiome in human acute graft-versus-host disease," Biology of Blood and Marrow Transplantation, vol. 19, pp. 329-332, 2013.

[165] B. E. de Pauw and J. P. Donnelly, "Infections in the immunocompromised host: general principles," in Mandell, Douglas, and Bennett's Principles and Practices of Infectious Diseases, G. L. Mandell, J. E. Bennett, and R. Dolin, Eds., pp. 3079-3090, 3174, Churchill Livingstone, Philadelphia, Pa, USA, 5th edition, 2000.

[166] M. M. Schubert, "Oral manifestations of viral infections in immunocompromised patients," Current Opinion in Dentistry, vol. 1, no. 4, pp. 384-397, 1991.

[167] S. Stevanovic, C. A. van Bergen, S. A. van Luxemburg-Heijs et al., "HLA-class II upregulation during viral infection leads to HLA-DP directed Graft-versus-Host Disease after CD4+ donor lymphocyte infusion," Blood, vol. 122, no. 11, pp. 1963-1973, 2013.

[168] N. Kawano, H. Gondo, T. Kamimura et al., "Chronic graftversus-host disease following varicella-zoster virus infection in allogeneic stem cell transplant recipients," International Journal of Hematology, vol. 78, no. 4, pp. 370-373, 2003.

[169] S. Elad, Y. Zadik, I. Hewson et al., "A systematic review of viral infections associated with oral involvement in cancer patients: a spotlight on Herpesviridea," Supportive Care in Cancer, vol. 18, no. 8, pp. 993-1006, 2010.

[170] P. Ljungman, R. de la Camara, N. Milpied et al., "Randomized study of valacyclovir as prophylaxis against cytomegalovirus reactivation in recipients of allogeneic bone marrow transplants," Blood, vol. 99, no. 8, pp. 3050-3056, 2002.

[171] M. Djuric, L. Jankovic, T. Jovanovic et al., "Prevalence of oral herpes simplex virus reactivation in cancer patients: a comparison of different techniques of viral detection," Journal of Oral Pathology and Medicine, vol. 38, no. 2, pp. 167-173, 2009.

[172] M. J. G. T. Rüping, C. Keulertz, J. J. Vehreschild et al., "Association of HSV reactivation and pro-inflammatory cytokine levels with the severity of stomatitis after BEAM chemotherapy and autologous SCT," Supportive Care in Cancer, vol. 19, no. 8, pp. 1211-1216, 2011.

[173] M. T. van der Beek, A. M. G. A. Laheij, J. E. Raber-Durlacher et al., "Viral loads and antiviral resistance of herpesviruses and oral ulcerations in hematopoietic stem cell transplant recipients," Bone Marrow Transplantation, vol. 47, pp. 12221228, 2012.

[174] S. B. Woo, S. T. Sonis, and A. L. Sonis, "The role of herpes simplex virus in the development of oral mucositis in bone marrow transplant recipients," Cancer, vol. 66, pp. 2375-2379, 1990.

[175] T. Allice, F. Cerutti, F. Pittaluga et al., "Evaluation of a novel realtime PCR system for cytomegalovirus DNA quantitation on whole blood and correlation with pp65-antigen test in guiding pre-emptive antiviral treatment," Journal of Virological Methods, vol. 148, no. 1-2, pp. 9-16, 2008.

[176] J. F. Correia-Silva, O. Bruna-Romero, R. G. Resende et al., "Saliva as a source of HCMV DNA in allogeneic stem cell transplantation patients," Oral Diseases, vol. 16, no. 2, pp. 210216, 2010.

[177] C. L. M. do Canto, C. F. H. Granato, E. Garcez et al., "Cytomegalovirus infection in children with down syndrome in a day-care center in Brazil," Revista do Instituto de Medicina Tropical de Sao Paulo, vol. 42, no. 4, pp. 179-183, 2000.

[178] J. B. Epstein, C. H. Sherlock, and R. A. Wolber, "Oral manifestations of cytomegalovirus infection," Oral Surgery Oral Medicine and Oral Pathology, vol. 75, no. 4, pp. 443-451, 1993.
[179] I. Nordøy, F. Müller, K. P. Nordal et al., "The role of the tumor necrosis factor system and interleukin-10 during cytomegalovirus infection in renal transplant recipients," Journal of Infectious Diseases, vol. 181, no. 1, pp. 51-57, 2000.

[180] C. Cervera, X. Filella, L. Linares et al., "TH1/TH2 cytokine release pattern during in vivo cytomegalovirus disease in solid organ transplantation," Transplantation Proceedings, vol. 39, no. 7, pp. 2233-2235, 2007.

[181] J. Cinatl Jr., J.-U. Vogel, R. Kotchetkov, M. Scholz, and H. W. Doerr, "Proinflammatory potential of cytomegalovirus infection. Specific inhibition of cytomegalovirus immediate-early expression in combination with antioxidants as a novel treatment strategy?" Intervirology, vol. 42, no. 5-6, pp. 419-424, 1999.

[182] A. Liu, Y. Ma, W. Wu et al., "Evaluation of human cytomegalovirus-specific CD8+ T-cells in allogeneic haematopoietic stem cell transplant recipients using pentamer and interferongamma-enzyme-linked immunospot assays," Journal of Clinical Virology, vol. 58, no. 2, pp. 427-431, 2013.

[183] A. M. Ngoma, K. Ikeda, Y. Hashimoto et al., "Impaired regulatory $\mathrm{T}$ cell reconstitution in patients with acute graft-versushost disease and cytomegalovirus infection after allogeneic bone marrow transplantation," International Journal of Hematology, vol. 95, no. 1, pp. 86-94, 2012.

[184] M. M. Schubert and D. E. Peterson, "Oral complications of hematopoietic cell transplantation," in Thomas' Hematopoietic Cell Transplantation: Stem Cell Transplantation, F. R. Appelbaum, S. J. Forman, R. S. Negrin et al., Eds., pp. 1589-1607, Wiley-Blackwell, Oxford, UK, 4th edition, 2009.

[185] L. A. Loevner, R. L. Karpati, P. Kumar, D. M. Yousem, W. Hsu, and K. T. Montone, "Posttransplantation lymphoproliferative disorder of the head and neck: imaging features in seven adults," Radiology, vol. 216, no. 2, pp. 363-369, 2000.

[186] S. Elad, C. Meyerowitz, M. Y. Shapira, M. Glick, M. Bitan, and G. Amir, "Oral posttransplantation lymphoproliferative disorder: an uncommon site for an uncommon disorder," Oral Surgery, Oral Medicine, Oral Pathology, Oral Radiology and Endodontology, vol. 105, no. 1, pp. 59-64, 2008.

[187] A. Barasch, E. Eisenberg, J. A. D’Ambrosio, K. Nuki, and D. E. Peterson, "Oral verruca vulgaris in a bone marrow transplant patient: a case report and review of literature," European Journal of Cancer B: Oral Oncology, vol. 32, no. 2, pp. 137-139, 1996.

[188] S. Steinbach, T. Hummel, C. Böhner et al., "Qualitative and quantitative assessment of taste and smell changes in patients undergoing chemotherapy for breast cancer or gynecologic malignancies," Journal of Clinical Oncology, vol. 27, no. 11, pp. 1899-1905, 2009.

[189] T. B. Comeau, J. B. Epstein, and C. Migas, "Taste and smell dysfunction in patients receiving chemotherapy: a review of current knowledge," Supportive Care in Cancer, vol. 9, no. 8, pp. 575-580, 2001.

[190] M. G. Marinone, D. Rizzoni, P. Ferremi, G. Rossi, T. Izzi, and C. Brusotti, "Late taste disorders in bone marrow transplantation: clinical evaluation with taste solutions in autologous and allogeneic bone marrow recipients," Haematologica, vol. 76, no. 6, pp. 519-522, 1991.

[191] I. G. M. van der Pas-van Voskuilen, J. S. J. Veerkamp, J. E. RaberDurlacher et al., "Long-term adverse effects of hematopoietic stem cell transplantation on dental development in children," Supportive Care in Cancer, vol. 17, no. 9, pp. 1169-1175, 2009.

[192] F. Demarosi, G. Lodi, A. Carrassi, D. Soligo, and A. Sardella, "Oral malignancies following HSCT: graft versus host disease 
and other risk factors," Oral Oncology, vol. 41, no. 9, pp. 865877, 2005.

[193] J. D. Rizzo, R. E. Curtis, G. Socié et al., "Solid cancers after allogeneic hematopoietic cell transplantation," Blood, vol. 113, no. 5, pp. 1175-1183, 2009.

[194] G. Aprile, M. Ramoni, D. Keefe, and S. Sonis, "Links between regimen-related toxicities in patients being treated for colorectal cancer," Current Opinion in Supportive and Palliative Care, vol. 3, no. 1, pp. 50-54, 2009.

[195] L. S. Elting, Y. C. Chang, and P. Parelkar, "Epidemiology and outcomes of regimen-related toxicities," in Pathobiology of Cancer Regimen-Related Toxicities, S. T. Sonis and D. M. Keefe, Eds., pp. 3-17, Springer, 2013.

[196] Y. Ye, G. Carlsson, M. B. Agholme et al., "Pretherapeutic plasma pro- and anti-inflammatory mediators are related to high risk of oral mucositis in pediatric patients with acute leukemia: a prospective cohort study," PLoS ONE, vol. 8, Article ID e64918, 2013.

[197] A. Khaw, R. Logan, D. Keefe, and M. Bartold, "Radiationinduced oral mucositis and periodontitis-proposal for an inter-relationship," Oral Diseases, vol. 20, no. 3, pp. e7-e18, 2013.

[198] T. E. van Dyke and A. J. van Winkelhoff, "Infection and inflammatory mechanisms," Journal of Periodontology, vol. 84, pp. S1-S7, 2013.

[199] J. Steinberg, J. Halter, H. Schiller, L. Gatto, and G. Nieman, "The development of acute respiratory distress syndrome after gut ischemia/reperfusion injury followed by fecal peritonitis in pigs: a clinically relevant model," Shock, vol. 23, no. 2, pp. 129137, 2005.

[200] L. M. Golub, J. B. Payne, R. A. Reinhardt, and G. Nieman, "Can systemic diseases co-induce (not just exacerbate) periodontitis? A hypothetical "two-hit" model," Journal of Dental Research, vol. 85, no. 2, pp. 102-105, 2006.

[201] S. Kaur, S. White, and P. M. Bartold, "Periodontal disease and rheumatoid arthritis: a systematic review," Journal of Dental Research, vol. 92, pp. 399-408, 2013.

[202] W. J. F. M. van der Velden, A. H. E. Herbers, T. Feuth, N. P. M. Schaap, J. Peter Donnelly, and N. M. A. Blijlevens, "Intestinal damage determines the inflammatory response and early complications in patients receiving conditioning for a stem cell transplantation," PLoS ONE, vol. 5, no. 12, Article ID e15156, 2010.

[203] E. Holler, K. Landfried, J. Meier, M. Hausmann, and G. Rogler, "The role of bacteria and pattern recognition receptors in GVHD," International Journal of Inflammation, vol. 2010, Article ID 814326, 6 pages, 2010. 


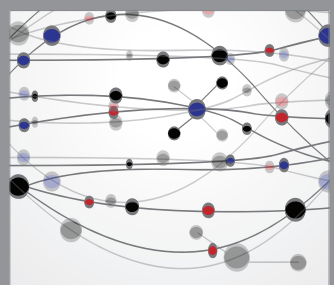

The Scientific World Journal
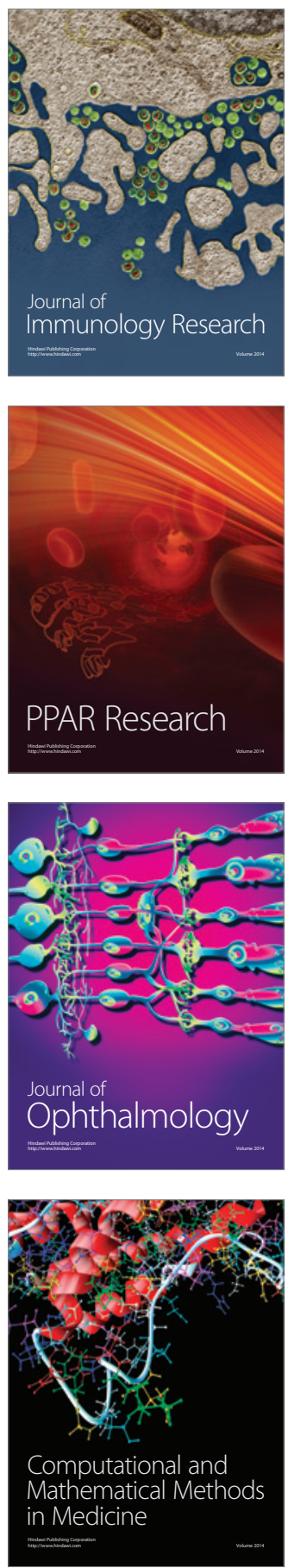

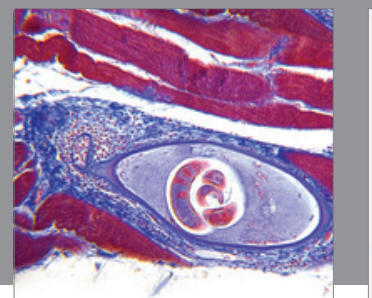

Gastroenterology

Research and Practice
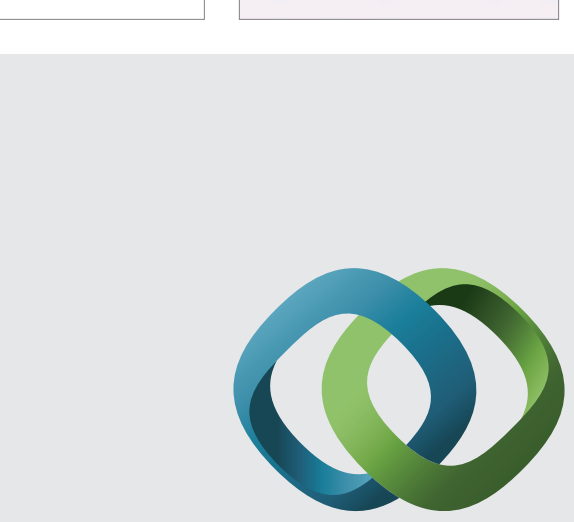

\section{Hindawi}

Submit your manuscripts at

http://www.hindawi.com
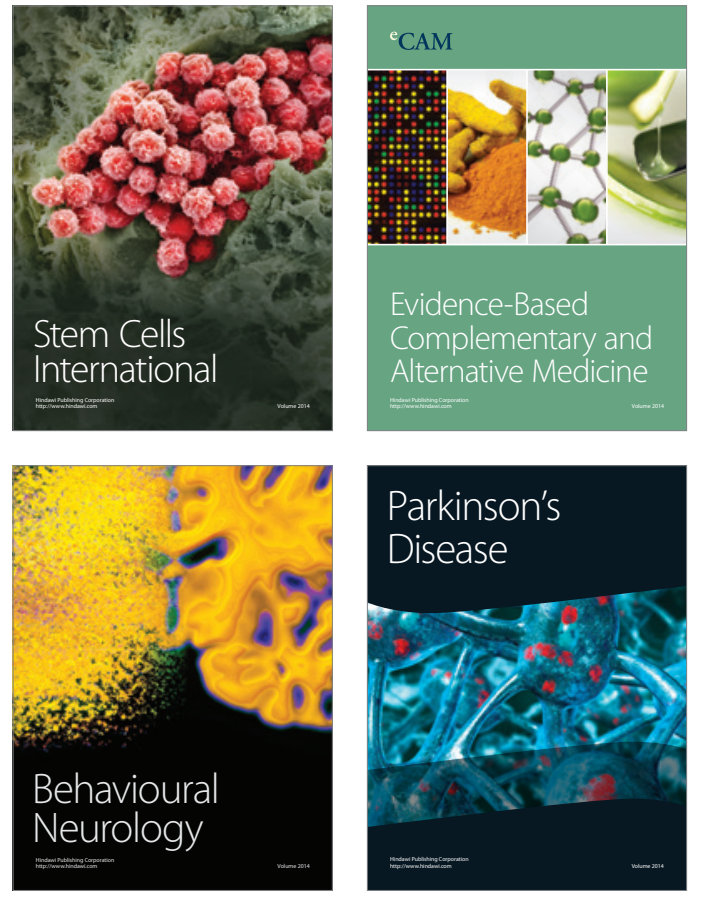
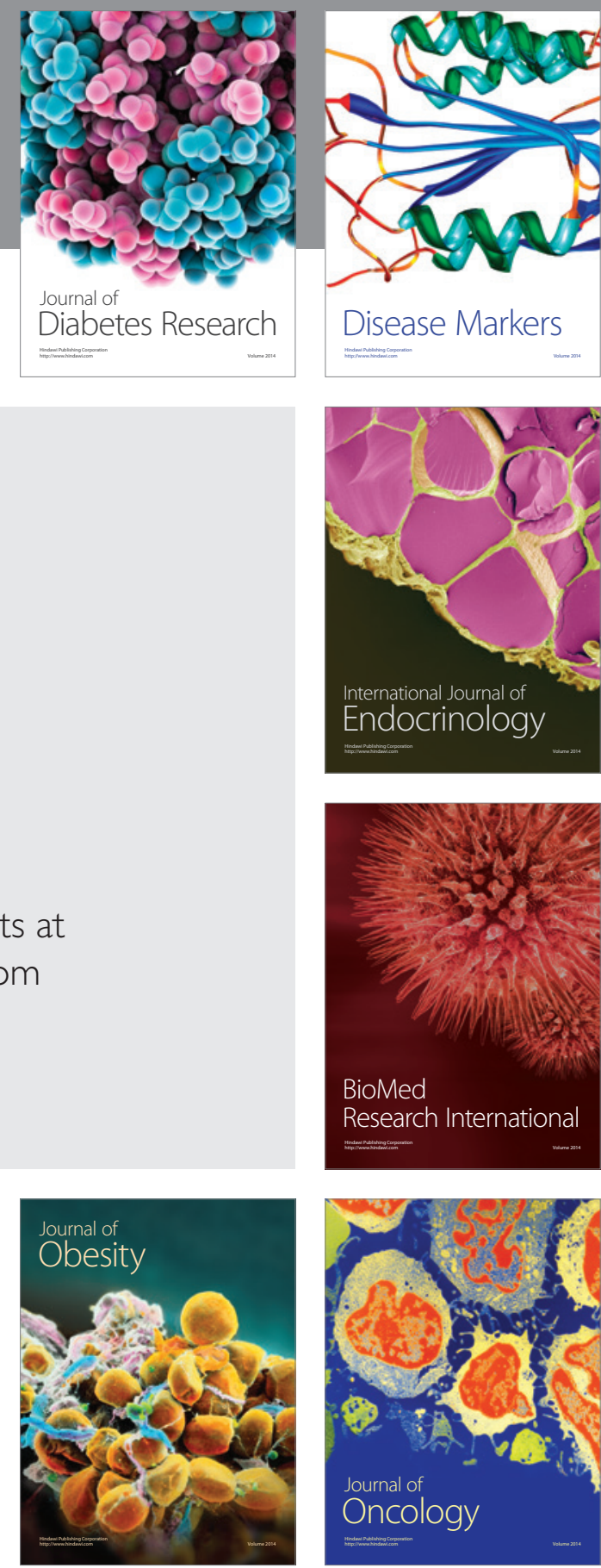

Disease Markers
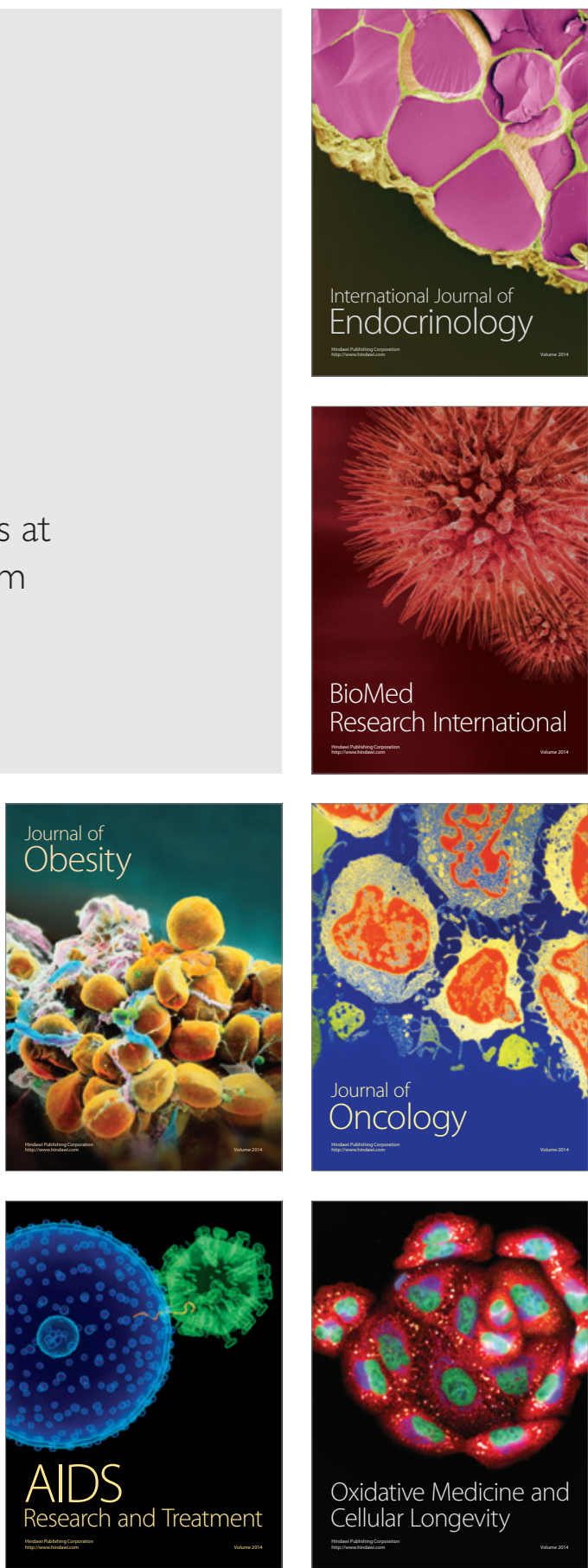